\title{
Warranty and price optimization in a competitive duopoly supply chain with parallel importation
}

\begin{abstract}
Gray market has always been an opposing challenge for manufacturers. Parallel markets tend to purchase the manufacturer's product at a lower price and resell it in another market with a higher price. In order to ameliorate the effects of parallel importation, the offering of a warranty for authorized channels is suggested as a competitive strategy. This paper considers two markets with different levels of willingness to pay. A manufacturer is present at both of these markets and offers the same product with different prices according to each market's willingness to pay. In the market with a lower willingness to pay, the manufacturer's product is not only purchased by a group of customers, but also by the parallel importer who later attempts to sell this product in the market with a higher willingness to pay. Moreover, in the market with lower willingness to pay, the manufacturer competes with another manufacturer that offers a similar product. A model for this problem is proposed when the manufacturer offers warranty as a competitive strategy against the parallel importer at the market with higher willingness to pay. Furthermore, a numerical example and a sensitivity analysis for the model are presented. Additionally, due to the practicality of this problem, managerial insights are included at the end of this research work.
\end{abstract}

Keywords: Gray market; parallel importation; warranty; price optimization; competitive supply chain.

\section{Introduction}

When genuine branded products are sold without official authorization by third parties is known as gray market. The problem of how to confront the diversion of products in an unauthorized channel (gray market) is an important concern for manufacturers. Regularly, in the gray market the manufacturer's product is sold cheaper than the manufacturer's authorized price but higher than the original price that they paid in order to make profit and compete with the manufacturer. According to Duhan and Sheffet (1988) these price differentials are caused by differences in demand, currency exchange rate or a segmentation strategy.

Online retail sector expands due to the progress of internet technology; which in turn helps boost gray markets. Ahmadi et al. (2015) mentioned that retailers such as Amazon, eBay, Alibaba, Kmart, and Costco are among those that sell gray products. Gray markets are divided into two groups: channel flow diversion and parallel importation. Channel flow diversion is mainly due to wholesale prices or other forms of sales offered by a manufacturer. Taking the advantage of the wholesale price the unauthorized channel purchases these products and attempts 
to resell them in retail in the same market or geographical zone. Although the channel flow diversion occurs often, it is also common to import products from another area or geographical zone in order to take advantage of the benefits of unofficial imports. For example, low costs of an unofficial importation and wide price discriminations across international markets result in higher profits. Parallel importations bring legitimately products. They are authorized for the original sale, and have no problem with their legality in their importation to a country. However, the parallel importations do not have the authorization of the local owner or patent holder of a copyright or trademark in order to be sold at the same market. Any company that provides products in different markets with different prices, for instance electronic devices such as cell phones, laptops, digital cameras, etc. may have to compete with parallel importers. Other than that, gray markets are also present at a variety of different markets. According to Christensen (2010) a gray market exists for dental products, such as dental implant products.

Unlike counterfeit products that are sold at black market, gray market products are bought directly or indirectly from the original manufacturer and these are authentic. However, companies are limited with respect to legal strategies available to eliminate these unauthorized channels. Therefore, it is critical to analyze the system with regards to the existence of parallel importations. According to Howell, et al. (1986) manufacturers need to offer a warranty in order to preserve their competitive advantage over the gray market. It is well known that a warranty is a liability of the manufacturer for its customer in order to compensate the customer if a product fails.

In fact the warranty means protect both manufacturer and customer. With respect to customer, the warranty is an insurance that compensates to buyer in case that the product is not up to its promised quality and functional features. On the other hand, Murthy and Djamaludin (2002) mentioned that with respect to manufacturer, the length of time and the predefined conditions save manufacturer from having to compensate to its buyer when she or he has misused or overused of the product. Moreover, warranty is viewed as a competitive strategy similar to price or quality. Menezes and Currim (1992) classify the failures that can occur after purchase of a product into three groups: initial, chance and wear-out failures. Initial failures occur during the break-in period at time $t=0$. Chance failures have a constant failure rate and occur at $t>0$. Wear-out failures happen after that product has functioned a certain length of time and these have a higher failure rate. Assuming that initial failures are immediately identified and solved, in this paper the warranty length is set based on chance failures, the second type of failures.

Even though warranty is recognized as a competitive strategy, sometimes the manufacturer chooses to set lower prices for its product. When customers have low levels of willingness to pay then manufacturer may decide not to offer the warranty. In this situation, in order to keep the price at a certain level, the warranty offered can be purchased with an additional cost. Customers may or may not select to pay for the warranty. That is why a manufacturer may offer warranty at one market and decide on not to offer it in another market.

Fundamentally, this paper aims to perform the following: 
- Introducing warranty as a practical factor for diminishing the effects of gray markets.

- Modeling the problem considering competition between two manufacturers, and competition between a manufacturer and a parallel importer.

- Identifying how warranty offered affects the competition between authorized and unauthorized channels.

- Comparing current work with those that ignore the warranty as a competing factor.

Furthermore, it is our intention to suggest some insights for managers that can help them in solving similar scenarios in real life.

The rest of this paper proceeds as follows. A review of the literature is presented in Section 2. Following that, the problem and its model are explained and presented in Section 3. A numerical example is described in Section 4. A sensitivity analysis is done in Section 5. Some managerial insights are provided in Section 6. Finally, the conclusion and some ideas for future research directions are given in Section 7.

\section{Literature review}

This paper is based on and contributes to several streams of literature such as it is reviewed in this section. Pricing problems between substitutable products often has been under consideration in the literature. Ma et al. (2012) examined the effects of a dominant manufacturer with substitutable products on members of the whole supply chain comprised of two manufacturers, one retailer, and several final consumers. Decision variables in their model are prices for each channel member. Zhao et al. (2012) developed a pricing problem of substitutable products of one manufacturer and two competitive retailers under fuzzy demands and manufacturer costs. Xu and Zhou (2012) considered two supply chains of one manufacturer and one retailer that sell substitutable products with quality and pricing competition between these supply chains as decision variables. With the help of game theory Li et al. (2013) determined the optimal prices and shelf-space allocation decisions for substitutable products in two competing retailers. Huang et al. (2013) investigated a two-echelon supply chain where one manufacturer produces substitutable products for multiple retailers. The decision variable for their model is the wholesale price for each of the retailers determined by a non-cooperative game. Zhao et al. (2014) analyzed how different competitive strategies of two manufactures affect the optimal pricing decisions of substitutable products in a two-echelon supply chain with firms' different channel powers structures. Wei and Zhao (2014) also assumed that both the customer demand and the manufacturing cost for each of the substitutable products are fuzzy variables. Their supply chain consisted of two manufacturers and one retailer and different game strategies are compared in several scenarios.

One important factor in our research is warranty. According to Blischke, (1993) free replacement warranties have been discussed in the literature often. Different aspects of warranty, including economical, operational, behavioral, marketing, and so much more, have been introduced and reviewed by Murthy and Djamaludin (2002). They also introduced several 
models previously presented in literature that analyze costs. Another review has been done by Chukova et al. (2005) which presented some statistical models and methods used to analyze warranty claims data. Wu (2012) summarized different types of data that are required in order to analyze warranty length, and later in another review $\mathrm{Wu}$ (2013) considered coarse warranty data. In a subsequent paper, $\mathrm{Wu}$ (2014) discussed warranty management with regard to return policies in products for which claim causes are unknown.

Chun and Tang (1995) developed a warranty model that determines the optimal price for the warranty considering the manufacturer's and the customers' risk. DeCroix (1999) dealt with the problem of durable products manufacturers in an oligopoly and determined the optimal solutions for product warranty, price, and reliability. He concluded that under general assumptions, each firm may set its reliability and warranty independently of price and other firms' actions. Li et al. (2011) discussed a supply chain with two competing manufacturers that each offer warranties on their respective product. Dai et al. (2012) utilized Nash equilibrium in a supply chain when order quantity is controlled by manufacturer and product quality by the supplier. They also compared warranty periods set by either the manufacturer, or the supplier in centralized and decentralized systems in order to determine optimal conditions under which better product quality as well as longer warranty is offered. Chen et al. (2012) reviewed the issues regarding pricing strategies in a supply chain comprised of a manufacturer and two competing retailers, in a Stackelberg game with the manufacturer as the leader, when the demand depends on warranty period. C.-H. Wu (2012) modeled and studied the equilibrium characteristics of effort and price in a supply chain with two manufacturers and a retailer. Lan et al. (2014) modeled a supply chain contract problem that considers pricing and warranty as buyer's decision variables under vague information which are presented as fuzzy variables in their model. Tsao et al. (2014) developed an aggregated model that considers pricing and inventory decisions for products with high technology under replacement warranty policy. Wei et al. (2014) used game theory approach to determine optimal price and warranty period of two complementary products in a duopoly supply chain with one common retailer. Modal et al. (2015) proposed a two-echelon supply chain with one manufacturer and one retailer considering that the demand function of customers depends on warranty, quality, and sales price of the product offered. They analyzed the supply chain under two centralized and decentralized scenarios.

The last important area that needs attention is the study of gray markets. Howell et al. (1986) are among the firsts who addressed gray markets by examining how price-quantity discounts facilitate the formation of alternative channels, more commonly referred to as gray markets. They offered tactics against gray markets. Cross et al. (1990) reviewed gray markets cases from a legal perspective. Also, Chaudhry (2014) presented the legal structures that allow gray markets operate in the United States and discussed the factors that encourage to form a gray market. Other papers have also dedicated their efforts to coordinate the channel in a way to prevent gray market's activities; see for example the research work of Su and Mukhopadhyay (2012). Some researchers saw the inevitability of the presence of gray markets and proposed control systems to curb gray market activities. Autrey et al. (2015) mentioned that the gray markets help to 
manufacturers of the exporting country make more profit. However, at the same time, the gray markets reduce the profit of the manufactures of the importing country. Another viable alternative for manufacturers in order to preserve a competitive advantage over the gray market is to offer a warranty. Jelovac and Bordoy (2005) developed a model to discuss the repercussions of allowing parallel imports of pharmaceuticals from one country to another. Ahmadi et al. (2015) mentioned that ignoring demand uncertainty may cause drastic decrease in the manufacturer's profit, and concluded that adjusting prices is more effective in controlling gray market activity than decreasing product availability. Jalali and Moghaddam (2014) stated that quality-price influence, price consciousness, risk averseness, perceived value are factors that affect the attitude of customers of gray markets.

There are some cases in which a model is developed in order to study the effect of parallel importation. Thompson (2009) mentioned that the presence of parallel imports causes that the prices drop. As it can be seen by reviewing the literature, from a legal point of view, there is not much one can do about the presence of parallel importation. While differential prices for different markets exist, the presence of gray markets is inevitable. Therefore, in order to attain control over the markets with gray marketers, manufacturers need to find ways to curb gray market activities. By reviewing the literature at hand, one of the most effective ways to ameliorate gray market's impacts is to offer warranty at that market in order to create a difference between manufacturer's product and the unauthorized product that gray marketer provides. To the best of our knowledge, despite the important role warranty plays in cases that firms compete with gray markets, this factor has so far been ignored in modeling a problem with parallel importation. Therefore, this paper includes warranty when it comes to model the competition when there exists parallel importation, in order to get a better grasp of how decision variables may be affected in the presence of parallel importation. The decision variables are: the price and warranty of the first manufacturer that competes with parallel importation, price of the other competing manufacturer with a substitutable product in the supply chain, and the price of the unauthorized channel; which are decision variables of the second manufacturer, and parallel importer, respectively.

\section{Problem description and modeling}

In this model two markets, market 1 and market 2, exist, each one with its own separate customers that may purchase products. Market 1 has a lower willingness to pay in comparison to market 2 with a higher willingness to pay. The two manufacturers in this model, manufacturer 1 and manufacturer 2, compete only in market 1 . Market 2 is monopolized by manufacturer 1 . Since market 1 has a lower willingness to pay, in order for manufacturer 1 to keep his/her price at a certain level, the warranty offered can be purchased with an additional cost. Therefore, in market 1 the warranty is treated as an accessory to the product and not as a part of it, whereas customers may or may not choose to pay for it. Manufacturer 1 only offers warranty on its product in market 2 that has a higher willingness to pay. Parallel importer is free to decide not to 

transferred with the product at the second market.

On the other hand, a third party distributer acts as a gray market in market 2, where he or she purchases the product of manufacturer 1 in market 1 with lower willingness to pay and attempts to sell this product in market 2 . It is obvious that the third party has no production costs in this scenario and the price that he or she sets in market 2 only should cover additional costs of transportation from market 1 to market 2. Furthermore, since the attractiveness of the gray market is the price difference between the imported product and manufacturer 1's product, then it can be expected that the gray market benefits if he or she sets a price lower than the price that manufacturer 1 sets for market 2 . If there exists little or no price difference between the manufacturer 1's product sold at market 1 and market 2, then gray market is unable to compete with the authorized channel. Figure 1 provides a graphic view of the supply chain in the presence of gray market. The decision variables for each of the participants in this model can also be seen in this figure. In table 1 a complete definition of notation is presented.

It is assumed that there are no leaks of demand between two markets, therefore, any change in the price of one market does not affect the demand of the other.

The demand function of each manufacturer $i, i=1,2$, at market 1 is as follows.

$$
q_{i 1}=1-\frac{p_{i 1}}{a_{1}}+\theta \frac{p_{k 1}}{a_{1}} \quad \forall i=1,2, \quad k=3-i
$$

Note that $0 \leq p_{i j} \leq a_{j}$ (Shavandi et al. (2014)). Therefore, $\frac{p_{i j}}{a_{j}}$ ensures that $q_{i j}$, the demand of manufacturer $i$ at market $j$, is a number between zero and one. In order to assign a lower degree of importance to the price of the other manufacturer than its own price, the price of the competing manufacturer is multiplied by $\theta, \theta \in[0,1]$. Note that the products of these two manufacturers are substitutable. Therefore, $\theta \in[0,1]$ is used as to define the level of substitutability. A value of $\theta$ close to 0 means that the two products are less substitutable. Thus, if $\theta$ is equal to 1 , it means that the products are completely substitutable.

Table 1. Notation

\begin{tabular}{ll}
\hline \multicolumn{2}{l}{ Notation } \\
\hline $\begin{array}{ll}\text { Parameters } \\
a_{j}\end{array} \quad$ maximum price set by manufacturers at market $j, j=1,2$ \\
$\theta$ & the level of substitutability between the products of manufacturer 1 and 2 \\
$r_{1}$ & Failure rate for product 1 \\
$c_{1}$ & Cost of replacement for manufacturer 1 for each unit of product 1 that fails \\
$\lambda$ & A multiplier of warranty that shows the effect on demand \\
$\delta$ & Decreasing effect of gray market- level of popularity of gray market \\
$c_{t}$ & Gray market's transportation cost for each unit of product transferred from market 1 to market 2. \\
$\tau$ & A multiplier of warranty to be compared with monetary values \\
\hline
\end{tabular}




\section{Variables \\ $p_{i j} \quad$ Price set by manufacturer $i, i=1,2$ at market $j, j=1,2$ \\ $q_{i j} \quad$ Demand for manufacturer $i, i=1,2$ at market $j, j=1,2$ \\ $W_{12} \quad$ Warranty time offered by manufacturer 1 at market 2 \\ $\pi_{M i} \quad$ Profit function for manufacturer $i, i=1,2$ \\ $p_{g} \quad$ Price set by gray market at market 1 \\ $q_{g} \quad$ Demand for gray market at market 2 \\ $\pi_{g} \quad$ Profit function for gray market}

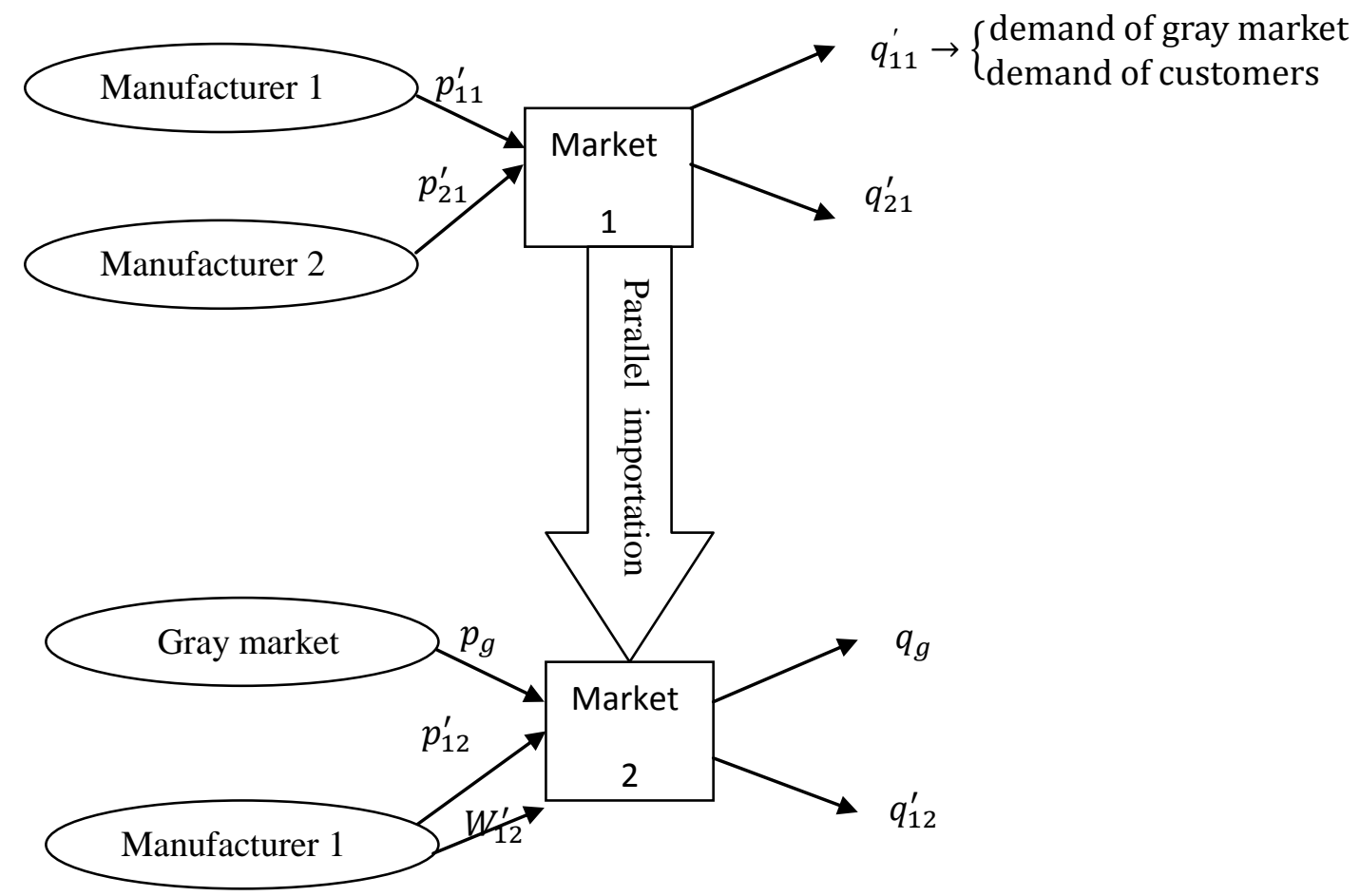

Figure 1. An illustration of the market 1 and market 2, the competition in each market and the decision variables of each participant

$W_{12}$ represents manufacturer 1 's warranty at market 2 , which is the length of time after purchase of manufacturer 1's product during which if the product fails, a new product is given to the customer. Since manufacturer 1 only offers warranty at market 2 and manufacturer 2 does not offer warranty, hence, $W_{11}=0, W_{21}=0, W_{12} \geq 0$. The rate at which product 1 fails, $r_{1}$, can also be viewed as reliability of the firm. Note that $r_{1}$ is not seen by customers. What they perceive as reliability of a firm, is the firm's warranty. Therefore, $r_{1}$ is not included in demand 

$\pi_{1}=f\left(p_{1}, W_{1}, \mathrm{r}_{1}\right)$.

In market 2 , the competition is between manufacturer 1 and the third party selling manufacturer 1's product. The demand function of manufacturer 1 at market 2 based on a uniform distribution for willingness to pay similar to that suggested by Shavandi, et al. (2014) is described in equation 2 .

$$
q_{12}=1-\frac{p_{12}}{a_{2}}+\lambda W_{12}
$$

In the demand function of the manufacturer 1 in market $2,0 \leq p_{12} \leq a_{2}$, which is similar to the prices that were explained for market 1 . It can easily be expected that those customers in market 2 that purchase the product from gray market have lower willingness to pay that those who purchase from authorized market. $\lambda$ is a multiplier for the warranty length in order to show the effect that the duration of warranty has on the demand of product 1 . Later, this paper further discusses the differences between these two customer groups.

First, the case without parallel importation is presented. Here, only competition exists between manufacturer 1 and 2 at market 1 and then this model is solved. Later, a case with parallel importation between two markets is carried out.

\subsection{Gray market channel does not exist}

In this scenario only authorized channels, which are manufacturer 1 and manufacturer 2 , compete in market 1 , whereas market 2 is monopolized by manufacturer 1 . In this paper, the manufacturer 1 offers warranty as a competitive strategy against the gray market. However, notice here that gray market is not present. Therefore, the manufacturer 1 offers warranty only at market 2 where he or she can set a higher price and is not willing to limit his/her profits of market 1 by adding the costs related to offering a warranty. The Nash equilibrium exists in market 1 between manufacturer 1 and manufacturer 2 . The profit function of manufacturer 1 in market 1 is modeled as follow

$$
\pi_{M 1}=q_{11} p_{11}+q_{12} p_{12}-r_{1} c_{1} q_{12}
$$

As it was mentioned earlier the profit function of the manufacturer that offers warranty depends on the failure rate of product, $r_{1}$, which creates additional costs of replacement or repair for the manufacturer, $c_{1}$. The $q_{1 j}$ 's can be replaced in the profit function in order to form equation (4).

$$
\pi_{M 1}=\left(1-\frac{p_{11}}{a_{1}}+\theta \frac{p_{21}}{a_{1}}\right) p_{11}+\left(1-\frac{p_{12}}{a_{2}}+\lambda W_{12}\right)\left(p_{12}-r_{1} c_{1}\right)
$$

On the other hand, the profit function of manufacturer 2 that is only present at market 1 is as follows.

$$
\pi_{M 2}=q_{21} p_{21}
$$


Due to the fact that manufacturer 2 does not offer warranty thus the cost of compensating a failed product is not considered in equation 5 .

Now, Equation 5 is rewritten as

$$
\pi_{M 2}=\left(1-\frac{p_{21}}{a_{1}}+\theta \frac{p_{11}}{a_{1}}\right) p_{21}
$$

Proposition 1. In the case without gray market, where the two manufacturers compete at market 1 and market 2 is monopolized by manufacturer 2, the optimal values for the decision variables of each manufacturer in each market are given as follows.

$p_{12}^{*}=r_{1} c_{1}$

$W_{12}^{*}=\frac{1}{\lambda}\left(\frac{r_{1} c_{1}}{a_{2}}-1\right)$

$p_{11}^{*}=\frac{a_{1}}{2-\theta}$

$p_{21}^{*}=\frac{a_{1}}{2-\theta}$

Note that, in the absence of third party distributer at market 1 , both manufacturers set the same price to compete with one another.

Proof. See Appendix A.

\subsection{Gray market channel- parallel importation exists}

Now, assume the scenario in which parallel importation between two markets occurs. In this case, the decision variables are shown with the prime symbol so that they can be distinguished from the decision variables in the previous subsection where gray market does not exist. It is assumed as in Sinha and Sarmah (2011) that the demand faced by each retailer not only depends on its own price and warranty duration, but also on the competing manufacturer's.

Market 2 is segmented into three parts. First segment consists of customers that have a high willingness to pay and purchase the authorized product of manufacturer 1 with warranty. This segment's utility function, $U_{1}$, is given by

$$
U_{1}=\alpha_{2}-p_{12}^{\prime}+\tau W_{12}^{\prime}
$$

Where $\tau$ is used as a multiplier of warranty so that it can be added to the other factors in equation 11 that are monetary values. The second segment of market 2 , those who purchase the imported product from market 1 , has lower willingness to pay in comparison with the first 
segment. Taking into account that a decreasing effect $(\delta)$ of willingness to pay in gray market occurs thus the utility function of this segment is expressed as

$$
U_{2}=\alpha_{2} \delta-p_{g}
$$

Let $\alpha_{2}$ be the maximum willingness to pay in market 2 and $p_{g}$ the price that the third party distributer charges for each unit of manufacturer 1's product in the gray market. It stands to reason that $p_{11}^{\prime} \leq p_{g}$, which means that the price of the imported product from market 1 has to be higher than the price of the manufacturer 1's product at market 1 for the parallel importer to have benefit from this transaction. Maximum willingness to pay for market 2 is obtained by equating (11) and (12) as below;

$$
\alpha_{2}-p_{12}^{\prime}+\tau W_{12}^{\prime}=\alpha_{2} \delta-p_{g} \rightarrow \alpha_{2}^{h}=\frac{p_{12}^{\prime}-\tau W_{12}^{\prime}-p_{g}}{1-\delta}
$$

Therefore, $\frac{p_{12}^{\prime}-\tau W_{12}^{\prime}-p_{g}}{1-\delta}$ is a balance point between segments one and two. If a customer has a willingness to pay lower than this value, then, that customer purchases the product offered by the third party. Any customer with a higher willingness to pay, purchases manufacturer 1's product that offers warranty.

Since the uniform distribution for willingness to pay in market 2 in the interval $\left[0, a_{2}\right]$ is $1 /\left(a_{2}-0\right)$, then the demand function of customers in segment one that purchase manufacturer 1 's product is showed as:

$$
q_{12}^{\prime}=\int_{\alpha_{2}^{h}}^{a_{2}} \frac{1}{a_{2}} d x=\left(a_{2}-\alpha_{2}^{h}\right) \frac{1}{a_{2}}=1+\frac{p_{g}+\tau W_{12}^{\prime}-p_{12}^{\prime}}{a_{2}(1-\delta)}
$$

The positive effect of warranty can be seen in the demand function, since, as the warranty time of product 1 increases, demand of this product increases in segment one. The third segment of market 2 includes people that do not purchase any of the products offered by neither the gray market nor manufacturer 1 . Thus, segment three's utility function is zero.

$$
U_{3}=0
$$

By equating the utility functions of segment two and three, equations (12) and (15), the value of the balance point of the maximum willingness to pay between the two lower segments is determined as follows;

$$
\alpha_{2} \delta-p_{g}=0 \rightarrow \alpha_{2}^{l}=\frac{p_{g}}{\delta}
$$


Where $\alpha_{2}^{l}$ represents the balance point of the willingness to pay of customers in segment two and segment three. It can be summarized that if the maximum willingness to pay of customers is between 0 to $\frac{p_{g}}{\delta}$, then, they are defined as segment three, and therefore do not purchase any of the products. If their willingness to pay is higher than $\frac{p_{g}}{\delta}$ but less than $\frac{p_{12}^{\prime}-\tau W_{12}^{\prime}-p_{g}}{1-\delta}$, then these customers belong to segment two that purchase parallel importation product. And finally, if customers' willingness to pay is greater than $\frac{p_{12}^{\prime}-\tau W_{12}^{\prime}-p_{g}}{1-\delta}$, it can be expected that they purchase manufacturer 1's product with warranty. Hence the demand function of the gray market, $q_{g}$, is computed as,

$q_{g}=\int_{\alpha_{2}^{\prime}}^{a_{2}^{h}} \frac{1}{a_{2}} d x=\left(\alpha_{2}^{h}-\alpha_{2}^{l}\right) \frac{1}{a_{2}}=\left(\frac{p_{12}^{\prime}-\tau W_{12}^{\prime}-p_{g}}{1-\delta}-\frac{p_{g}}{\delta}\right) \frac{1}{a_{2}}$

$q_{g}=\frac{\delta p_{12}^{\prime}-\delta \tau W_{12}^{\prime}-p_{g}}{\delta(1-\delta) a_{2}}$

Total demand for market 2 is from segments one and two. Thus,

$$
q_{12}^{\prime}+q_{g}=1+\frac{p_{g}+\tau W_{12}^{\prime}-p_{12}^{\prime}}{a_{2}(1-\delta)}+\frac{\delta p_{12}^{\prime}-\delta \tau W_{12}^{\prime}-p_{g}}{\delta(1-\delta) a_{2}}=1-\frac{p_{g}}{\delta a_{2}}
$$

If the price of parallel importation is set to zero, then the maximum potential demand, which is equal to 1 , is reached. The profit function of parallel importation is given below

$$
\pi_{g}=q_{g}\left(p_{g}-p_{11}^{\prime}-c_{t}\right)
$$

Where $c_{t}$ is the transportation cost that third party faces when importing each unit of product from market 1 to market 2. In order to compute the profit of the gray market, all costs, including purchase cost and transportation cost for each unit is subtracted from the price that the gray market is charging for each unit of product. By setting the value for demand, profit function for parallel importation is expressed as

$$
\pi_{g}=\frac{\delta p_{12}^{\prime}-\delta \tau W_{12}^{\prime}-p_{g}}{\delta(1-\delta) a_{2}}\left(p_{g}-p_{11}^{\prime}-c_{t}\right)
$$

It can be seen that both markets contribute to the profit of manufacturer 1. In market 1 , not only the demand of manufacturer 1 is purchased by customers from this manufacturer, but also the demand for the gray market, $q_{g}$, is also attained from manufacturer 1, therefore, the total demand for market 1 is $q_{11}^{\prime}+q_{g}$. Therefore, the profit function of manufacturer 1 is 
$\pi_{M 1}^{\prime}=\left(q_{11}^{\prime}+q_{g}\right) p_{11}^{\prime}+q_{12}^{\prime} p_{12}^{\prime}-q_{12}^{\prime} r_{1} c_{1}$

If the demand functions are inserted into equation (21) then the profit function of manufacturer 1 becomes

$$
\pi_{M 1}^{\prime}=\left[\left(1-\frac{p_{11}^{\prime}}{a_{1}}+\theta \frac{p_{21}^{\prime}}{a_{1}}\right)+\frac{\delta p_{12}^{\prime}-\delta \tau W_{12}^{\prime}-p_{g}}{\delta(1-\delta) a_{2}}\right] p_{11}^{\prime}+\left[1-\frac{p_{12}^{\prime}-\tau W_{12}^{\prime}-p_{g}}{a_{2}(1-\delta)}\right]\left(p_{12}^{\prime}-r_{1} c_{1}\right)
$$

The profit function of manufacturer 2 in market 1 is

$$
\pi_{M 2}^{\prime}=q_{21}^{\prime} p_{21}^{\prime}=\left(1-\frac{p_{21}^{\prime}}{a_{1}}+\theta \frac{p_{11}^{\prime}}{a_{1}}\right) p_{21}^{\prime}
$$

Proposition 2. In the presence of gray market, the optimal values for the decision variables of each manufacturer in their markets and the parallel importation are as follows.

$$
\begin{aligned}
& p_{11}^{\prime *}=\frac{a_{1} a_{2} \delta(\delta-1)\{(2-\delta)(\theta+2)+2\}-2 a_{1} c_{t}(\delta-1)}{\left(\theta^{2}-4\right) \delta(1-\delta)(2-\delta) a_{2}+2 a_{1}(\delta-1)} \\
& W_{12}^{\prime *}=\frac{(2-\delta) r_{1} c_{1}-2 a_{2}(1-\delta)-c_{t}}{\tau(2-\delta)}+\frac{(1-\delta)}{(2-\delta) \tau} \frac{a_{1} a_{2} \delta(\delta-1)\{(2-\delta)(\theta+2)+2\}-2 a_{1} c_{t}(\delta-1)}{\left(\theta^{2}-4\right) \delta(1-\delta)(2-\delta) a_{2}+2 a_{1}(\delta-1)} \\
& p_{12}^{\prime *}=r_{1} c_{1}+\frac{a_{1} a_{2} \delta(\delta-1)\{(2-\delta)(\theta+2)+2\}-2 a_{1} c_{t}(\delta-1)}{\left(\theta^{2}-4\right) \delta(1-\delta)(2-\delta) a_{2}+2 a_{1}(\delta-1)} \\
& p_{21}^{\prime *}=\frac{a_{1}}{2}+\frac{\theta}{2} \frac{a_{1} a_{2} \delta(\delta-1)\{(2-\delta)(\theta+2)+2\}-2 a_{1} c_{t}(\delta-1)}{\left(\theta^{2}-4\right) \delta(1-\delta)(2-\delta) a_{2}+2 a_{1}(\delta-1)} \\
& p_{g}^{*}=\frac{a_{2} \delta(1-\delta)+c_{t}}{(2-\delta)} \frac{1}{(2-\delta)} \frac{a_{1} a_{2} \delta(\delta-1)\{(2-\delta)(\theta+2)+2\}-2 a_{1} c_{t}(\delta-1)}{\left(\theta^{2}-4\right) \delta(1-\delta)(2-\delta) a_{2}+2 a_{1}(\delta-1)}
\end{aligned}
$$

Proof. See Appendix B.

\section{Numerical example}

In this section a numerical example is illustrated and solved. As it was mentioned before this problem is of practical nature. The electronics business is one of the fields in which this problem can be observed. In this numerical example, a digital camera is produced by two different manufacturers. These cameras are considered substitutable. Both manufacturers sell their cameras, at their Asia market. Manufacturer 1 also plans to sell his camera at the USA market for 
which he offers warranty. The market at USA has a higher willingness to pay in comparison to Asia market. The camera sold by manufacturer 1 at Asia market is also purchased by a third party distributer at large quantities that are later transported to USA market in order to be sold at a higher price than Asia market and a lower price than USA market. This results in a competition between manufacturer 1 and the parallel importer.

First assume a scenario where there is no third party distributer. Assume that USA market with higher willingness to pay, may have $a_{2}=0.5$. Asia market may set a lower price than this, therefore, the maximum price for Asia market is $a_{1}=0.4$. Manufacturer 1 and manufacturer 2 produce a substitutable camera in the same market. Due to the similarities in these cameras the substituting factor between these two products is estimated as $\theta=0.8$. Manufacturer 1 also attempts to sell his product at market 2, where in the scenario with parallel importation, he competes with the gray market. The camera produced by manufacturer 1 has a 60 -percent chance of failure, $r_{1}=0.6$, in which case the cost that manufacturer 1 faces is $c_{1}=0.9$ which includes the losses due to bad reputation. This cost is only included in the model for market 2 where he offers warranty as a marketing strategy. The transportation costs for the third party distributer from market 1 to market 2 is $c_{t}=0.02$. Moreover let $\lambda=0.2, \tau=0.3$, and $\delta=0.6$.

First, it is assumed that there is no gray market. At market 1 , two manufacturers compete and in market 2, only manufacturer 1 attempts to sell his product. The results for this scenario are shown in the first two columns of Table 2.

In the second scenario, the gray market purchases the camera at Asia market and resells it at a higher price at the USA market, the results are summarized in the last two columns of Table 2. It can be seen in Table 2 that manufacturer 1 tends to offer a lower price at market 1 , a higher price at market 2 , and a higher warranty duration, when comparing scenario 1 with scenario 2 , and by doing so, he almost doubles his own profit when he competes with the parallel importer. However, manufacturer 2 sets a lower price at market 1 which in turn creates less profit.

Table 2. Summary of results in the without and with gray market scenarios

\begin{tabular}{lccl}
\hline \multicolumn{2}{c}{ without gray market } & \multicolumn{2}{c}{ with gray market } \\
\hline$p_{11}$ & 0.3333333 & $p_{11}^{\prime}$ & 0.3140376 \\
\hline$p_{21}$ & 0.3333333 & $p_{21}^{\prime}$ & 0.3256151 \\
$p_{12}$ & 0.54 & $p_{12}^{\prime}$ & 0.8540376 \\
$W_{12}$ & 0.4 & $W_{12}^{\prime}$ & 1.099083 \\
$\pi_{M 1}$ & 0.2777777 & $p_{g}$ & 0.3243126 \\
$\pi_{M 2}$ & 0.2777777 & $\pi_{M 1}^{\prime}$ & 0.2465491 \\
& & $\pi_{M 2}^{\prime}$ & 0.2650629 \\
& & $\pi_{g}$ & $0.7881361 \mathrm{E}-03$ \\
\hline
\end{tabular}




\section{Sensitivity analysis}

\subsection{The scenario without the presence of the gray market}

As it can be observed in Figure 2, since the willingness to pay for market 2 is higher than willingness to pay in market 1 , the price set by manufacturer 1 for the product in market 2 is higher than that of market 1 at all times. The curve for the equal prices set by both manufacturers in market 1 is dependent on $\theta$, whereas in market 2 , it is not. That is because, in market 2 the competition between two manufacturers does not exist. Figure 3 shows market 1's prices with respect to $\theta$ for different values of $a_{1}$. Since the willingness to pay for market 1 is always lower than that of market 2 , it stands to reason that it is only considered those values less that $a_{2}$, therefore, $a_{1}$ 's range is from 0.5 to 0.01 . As the willingness to pay in market 1 increases, both manufacturers tend to set higher values for their price. Additionally, as the compatibility between the two products increases, the manufacturers set a higher price. It was mentioned earlier that the price set by manufacturer 1 at market 2 does not depend on $\theta$, hence, $p_{12}$ is shown as a straight line in Figure 4. However, as the willingness to pay at market 2 increases, manufacturer 1 sets a higher price for its product, i.e. if the customers are more willing to pay, then manufacturer 1 chooses a higher price in order to increase his benefits.

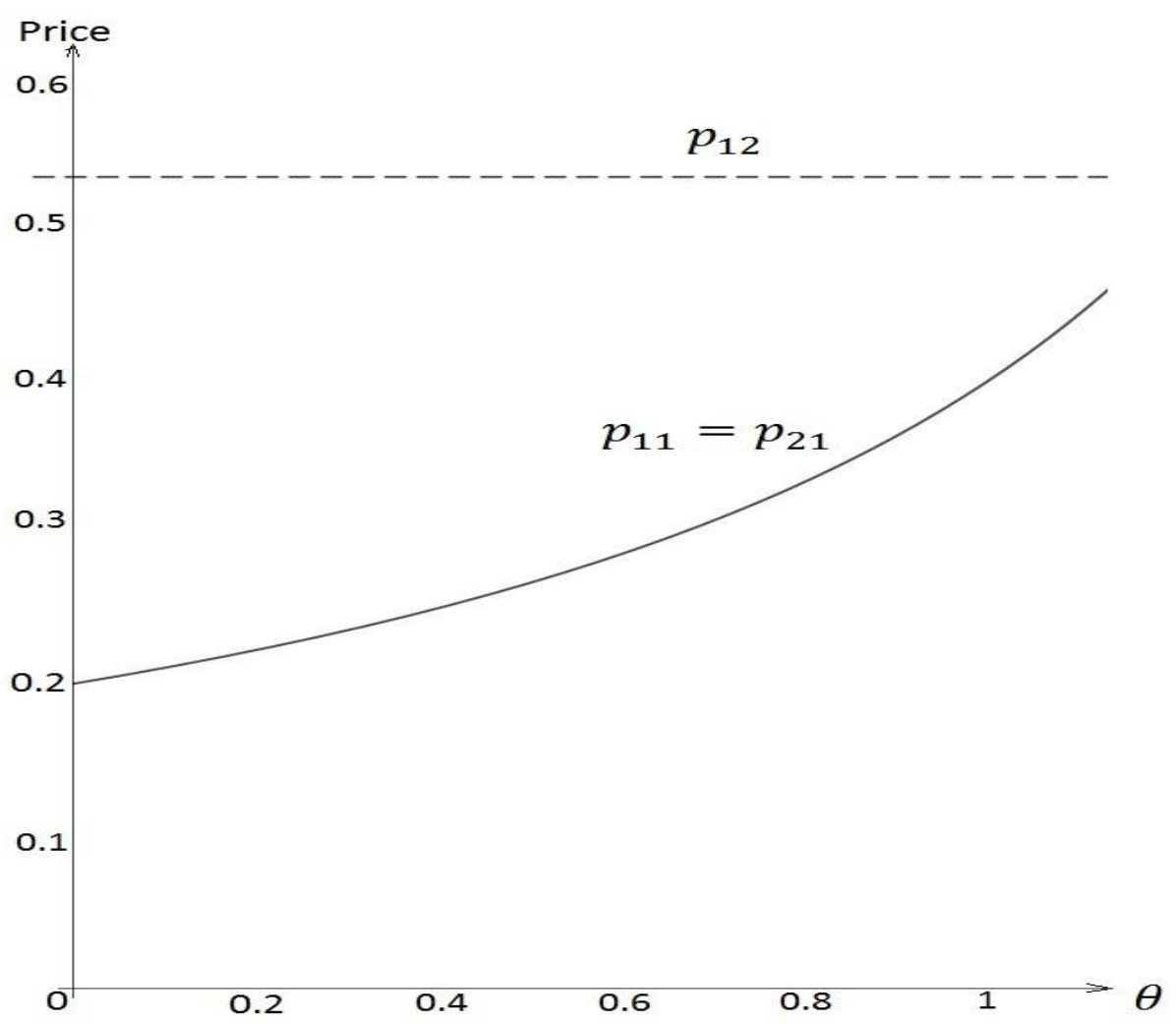

Figure 2. Price differences in both markets with respect to $\theta$. 


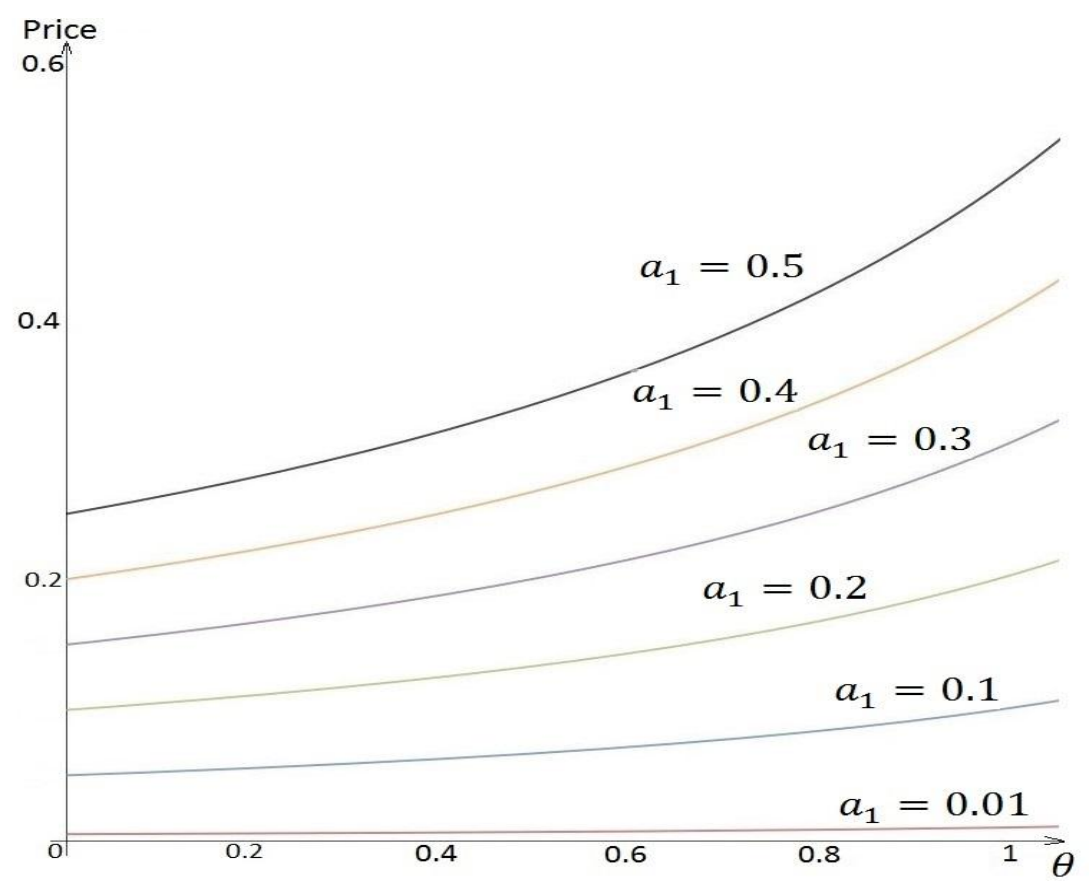

Figure 3. Equal prices of market 1, $p_{11}$ and $p_{21}$, with respect to $\theta$ for different values of $a_{1}$.

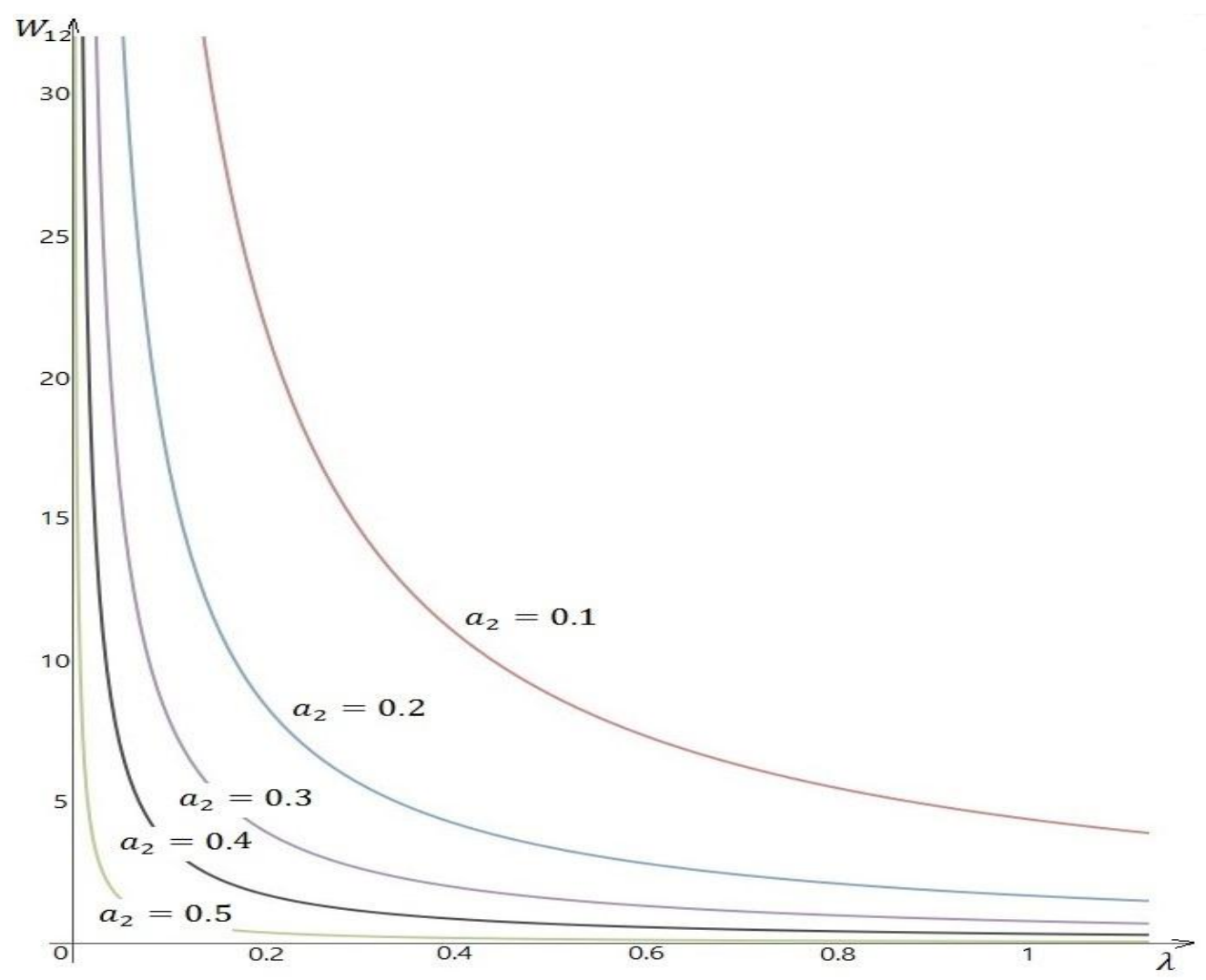

Figure 4. Warranty for manufacturer 1 's product at market $2, W_{12}$ with respect to $\lambda$ for different values of $a_{2}$. 
Table 3. The effect of $\theta$ and $a_{1}$ on every decision variable without the presence of gray market

\begin{tabular}{clcccccc}
\hline$\theta$ & $a_{1}$ & $p_{11}$ & $p_{21}$ & $p_{12}$ & $W_{12}$ & $\pi_{M 1}$ & $\pi_{M 2}$ \\
\hline 0.2 & 0.01 & 0.0056 & 0.0056 & 0.54 & 0.4 & 0.0031 & 0.0031 \\
0.2 & 0.1 & 0.0556 & 0.0556 & 0.54 & 0.4 & 0.0309 & 0.0309 \\
0.2 & 0.2 & 0.1111 & 0.1111 & 0.54 & 0.4 & 0.0617 & 0.0617 \\
0.2 & 0.3 & 0.1667 & 0.1667 & 0.54 & 0.4 & 0.0926 & 0.0926 \\
0.2 & 0.4 & 0.2222 & 0.2222 & 0.54 & 0.4 & 0.1234 & 0.1234 \\
0.2 & 0.5 & 0.2778 & 0.2778 & 0.54 & 0.4 & 0.1543 & 0.1543 \\
0.4 & 0.01 & 0.0062 & 0.0062 & 0.54 & 0.4 & 0.0039 & 0.0039 \\
0.4 & 0.1 & 0.0625 & 0.0625 & 0.54 & 0.4 & 0.0391 & 0.0391 \\
0.4 & 0.3 & 0.1875 & 0.1875 & 0.54 & 0.4 & 0.1172 & 0.1172 \\
0.4 & 0.5 & 0.3125 & 0.3125 & 0.54 & 0.4 & 0.1953 & 0.1953 \\
0.6 & 0.01 & 0.0071 & 0.0071 & 0.54 & 0.4 & 0.0051 & 0.0051 \\
0.6 & 0.1 & 0.0714 & 0.0714 & 0.54 & 0.4 & 0.0510 & 0.0510 \\
0.6 & 0.3 & 0.2143 & 0.2143 & 0.54 & 0.4 & 0.1531 & 0.1531 \\
0.6 & 0.5 & 0.3571 & 0.3571 & 0.54 & 0.4 & 0.2551 & 0.2551 \\
0.8 & 0.01 & 0.0083 & 0.0083 & 0.54 & 0.4 & 0.0069 & 0.0069 \\
0.8 & 0.1 & 0.083 & 0.083 & 0.54 & 0.4 & 0.0694 & 0.0694 \\
0.8 & 0.3 & 0.25 & 0.25 & 0.54 & 0.4 & 0.2083 & 0.2083 \\
0.8 & 0.5 & 0.4167 & 0.4167 & 0.54 & 0.4 & 0.3472 & 0.3472 \\
\hline
\end{tabular}

Table 4. The effects of $\theta$ and $a_{2}$ on every decision variable without the presence of gray market (Note that since $a_{1}$ must always be lower than $a_{2}$ in this table for each value of $a_{2}, a_{1}$ is assumed the half $a_{2}$ value. For instance, in the first row that $a_{2}=0.1$, the value for $a_{1}$ would be 0.05 )

\begin{tabular}{cccccccc}
\hline$\theta$ & $a_{2}$ & $p_{11}$ & $p_{21}$ & $p_{12}$ & $W_{12}$ & $\pi_{M 1}$ & $\pi_{M 2}$ \\
\hline 0.2 & 0.1 & 0.0278 & 0.0278 & 0.54 & 22 & 0.0154 & 0.0154 \\
0.2 & 0.2 & 0.0556 & 0.0556 & 0.54 & 8.5 & 0.0309 & 0.0309 \\
0.2 & 0.3 & 0.0833 & 0.0833 & 0.54 & 4 & 0.0463 & 0.0463 \\
0.2 & 0.4 & 0.1111 & 0.1111 & 0.54 & 1.75 & 0.0617 & 0.0617 \\
0.2 & 0.5 & 0.1389 & 0.1389 & 0.54 & 0.4 & 0.0772 & 0.0772 \\
0.4 & 0.1 & 0.0313 & 0.0313 & 0.54 & 22 & 0.0195 & 0.0195 \\
0.4 & 0.3 & 0.0937 & 0.0937 & 0.54 & 4 & 0.0586 & 0.0586 \\
0.4 & 0.5 & 0.1563 & 0.1563 & 0.54 & 0.4 & 0.0977 & 0.0977 \\
0.6 & 0.1 & 0.0357 & 0.0357 & 0.54 & 22 & 0.0255 & 0.0255 \\
0.6 & 0.3 & 0.1071 & 0.1071 & 0.54 & 4 & 0.0765 & 0.0765 \\
0.6 & 0.5 & 0.1786 & 0.1786 & 0.54 & 0.4 & 0.1276 & 0.1276 \\
0.8 & 0.1 & 0.0417 & 0.0417 & 0.54 & 22 & 0.0347 & 0.0347 \\
0.8 & 0.3 & 0.1250 & 0.1250 & 0.54 & 4 & 0.1042 & 0.1042 \\
0.8 & 0.5 & 0.2083 & 0.2083 & 0.54 & 0.4 & 0.1736 & 0.1736 \\
\hline
\end{tabular}


Table 5. The effect of $\lambda$ and $a_{2}$ on warranty time offered by manufacturer 1 at market 2 without the presence of gray market (Note that since $a_{1}$ must always be lower than $a_{2}$ in this table for each value of $a_{2}, a_{1}$ is assumed the half $a_{2}$ value. For instance, in the first row that $a_{2}=0.1$, the value for $a_{1}$ would be 0.05 )

\begin{tabular}{ccc}
\hline$\lambda$ & $\mathrm{a}_{2}$ & $W_{12}$ \\
\hline 0.01 & 0.1 & 440 \\
0.1 & 0.1 & 44 \\
0.3 & 0.1 & 14.667 \\
0.5 & 0.1 & 8.8 \\
0.7 & 0.1 & 6.285 \\
0.9 & 0.1 & 4.889 \\
0.01 & 0.2 & 170 \\
0.1 & 0.2 & 17 \\
0.3 & 0.2 & 5.667 \\
0.5 & 0.2 & 3.4 \\
\hline
\end{tabular}

\begin{tabular}{ccc}
\hline$\lambda$ & $\mathrm{a}_{2}$ & $W_{12}$ \\
\hline 0.7 & 0.2 & 2.43 \\
0.9 & 0.2 & 1.889 \\
0.01 & 0.3 & 80 \\
0.1 & 0.3 & 8 \\
0.3 & 0.3 & 2.667 \\
0.5 & 0.3 & 1.6 \\
0.7 & 0.3 & 1.143 \\
0.9 & 0.3 & 0.889 \\
0.01 & 0.4 & 35 \\
0.1 & 0.4 & 3.5 \\
\hline
\end{tabular}

\begin{tabular}{ccc}
\hline$\lambda$ & $\mathrm{a}_{2}$ & $W_{12}$ \\
\hline 0.3 & 0.4 & 1.667 \\
0.5 & 0.4 & 0.7 \\
0.7 & 0.4 & 0.5 \\
0.9 & 0.4 & 0.389 \\
0.01 & 0.5 & 8 \\
0.1 & 0.5 & 0.8 \\
0.3 & 0.5 & 0.267 \\
0.5 & 0.5 & 0.16 \\
0.7 & 0.5 & 0.114 \\
0.9 & 0.5 & 0.089 \\
\hline
\end{tabular}

\subsection{The scenario with the presence of the gray market}

In this section the analysis is performed based on the scenario in which manufacturer 1 competes with manufacturer 2 at market 1, and competes with the gray market at market 2 .

In Figure 5, the price of each manufacturer at market 1 is illustrated in a three-dimensional plot with respect to increases in $\delta$ and $\theta$. It can be observed that both prices show similar performances with respect to $\delta$ and $\theta$. However these variations are more tangible when it comes to the price of manufacturer 1 . Moreover, it can be concluded that manufacturer 2 sets higher prices that manufacturer 1 . Figure 5-a shows that as $\theta$ increases, $p_{11}^{\prime}$ always increases as well, whereas, with an increase in $\delta$, at first $p_{11}^{\prime}$ increases as well, but after a point near the middle, the slope is negative and $p_{11}^{\prime}$ decreases. It can be observed in Figure 5-b that for any value of $\delta$, when $\theta=0$ then $p_{21}^{\prime}=0.2$ and is not related to the price that manufacturer 1 chooses. The price set by manufacturer 2 is directly related to marker 1's willingness to pay, the level of compatibility, and the price set by manufacturer 1 . Manufacturer 1 compensates this lower price by setting a higher price at market 2 when he is in competition with the parallel importer (See Figure 6). Parallel importer sets a higher price than $p_{11}^{\prime}$ and a lower price than $p_{12}^{\prime}$ at all times in order to be able to compete with manufacturer 1 . In Figure 6-a, as $\delta$ increases then $p_{12}^{\prime}$ increases as well, to the point where as $\delta$ increases $p_{12}^{\prime}$ decreases. In Figure 6-b the same thing happens to the price that is set by parallel importer in market 2 as $\delta$ increases. As the attention to the gray market, $\delta$ increases, gray market raises his price, then, at a value near 0.6 this effect reverses. However, as $\theta$ increases between the values of $\delta$ in $(0,1)$, gray market sets a higher price. When 
products are more substitutable, then gray market has a good chance to exist, a higher price is set for the gray market, since $p_{11}^{\prime}$ also increases when this happens. Figure 7 illustrates the warranty plot with respect to $\delta$ and $\theta$ for two different values of $\tau$. When $\tau=0.3$, the plot has a higher slop in comparison with $\tau=0.7$, moreover, $\tau=0.3$ attains higher values for the manufacturer 1 's warranty length when compared to $\tau=0.7$.

\section{Managerial insights}

Due to the practicality of this problem, and similarities between aforementioned scenarios in real life, with electrical devices such as the example of the digital camera market discussed in Section 4 and other products, it is our intention to suggest some managerial insights that can be concluded from this research work.

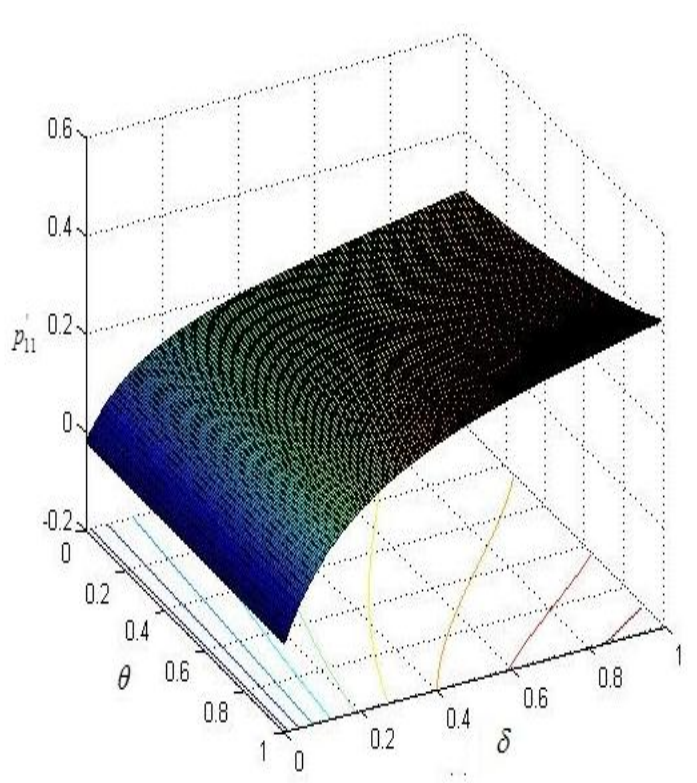

(a)

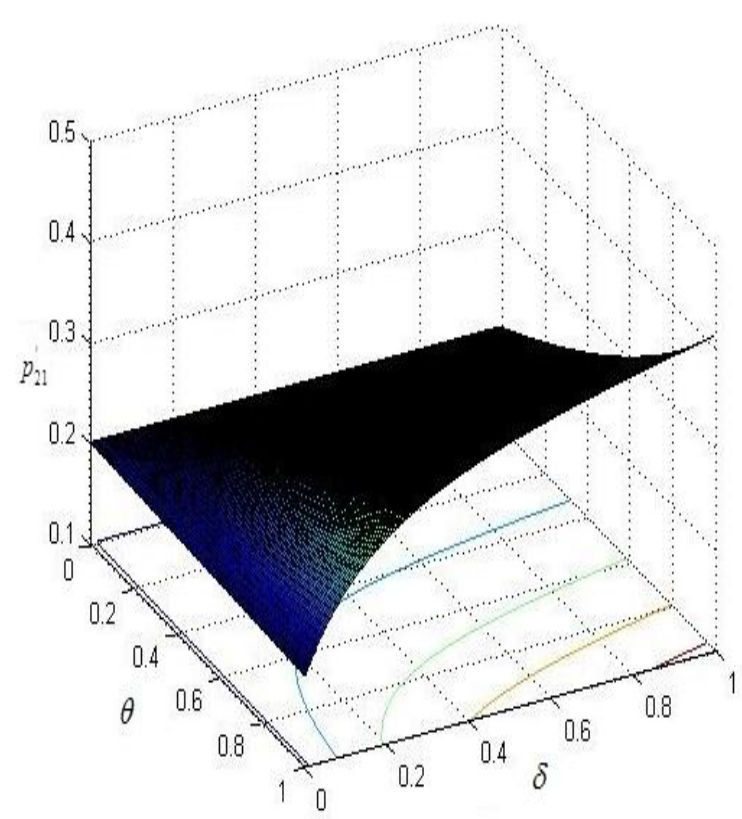

(b)

Figure 5. Price curves at market 1 with respect to $\delta$ and $\theta$ for (a) manufacturer 1's product and (b) manufacturer 2's product 


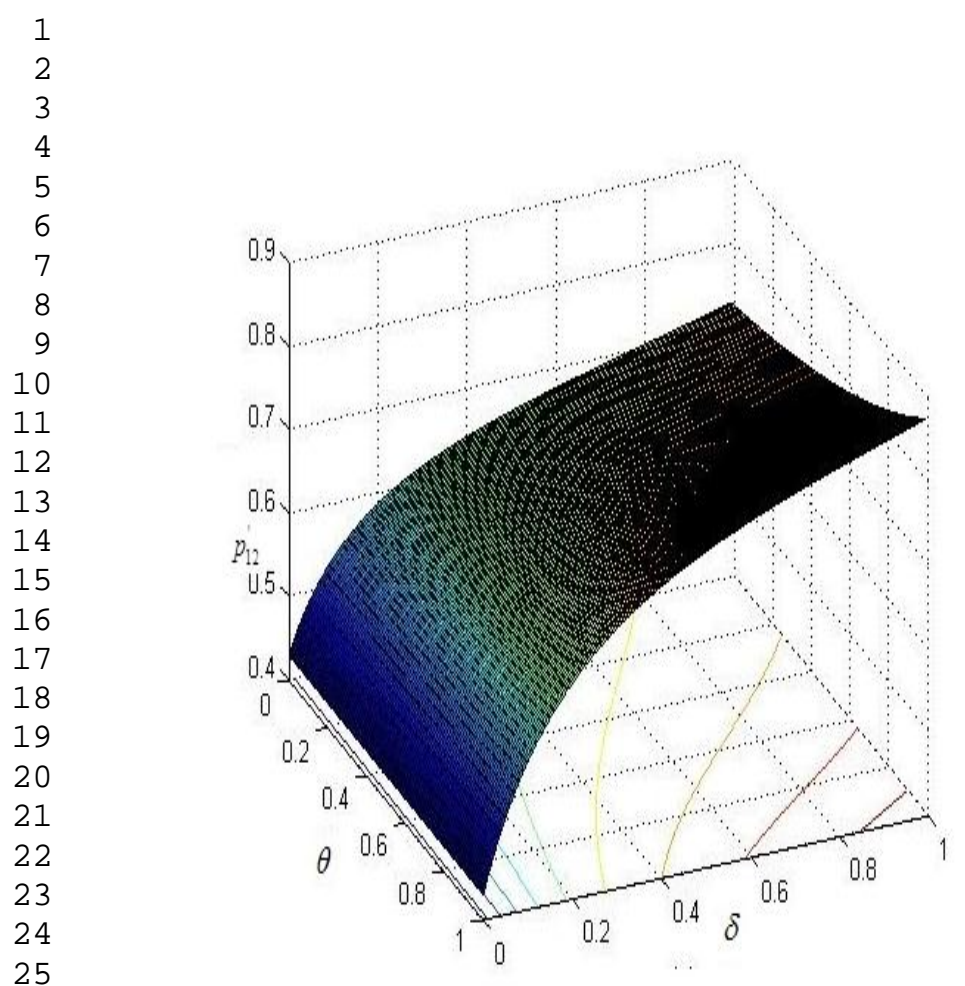

(a)

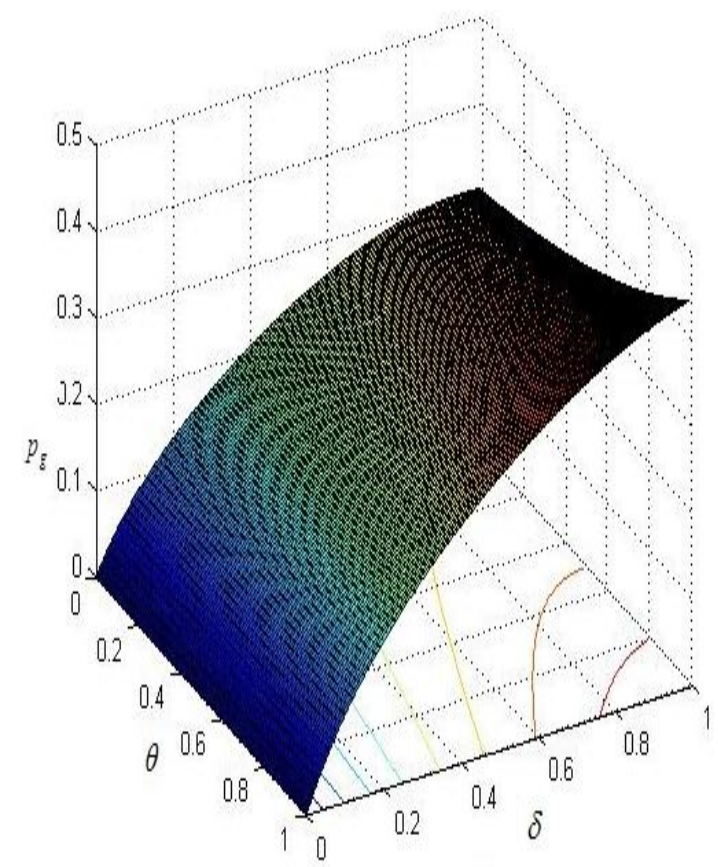

(b)

Figure 6. Price curves at market 2 with respect to $\delta$ and $\theta$ for (a) manufacturer 1's product and (b) parallel importer's product

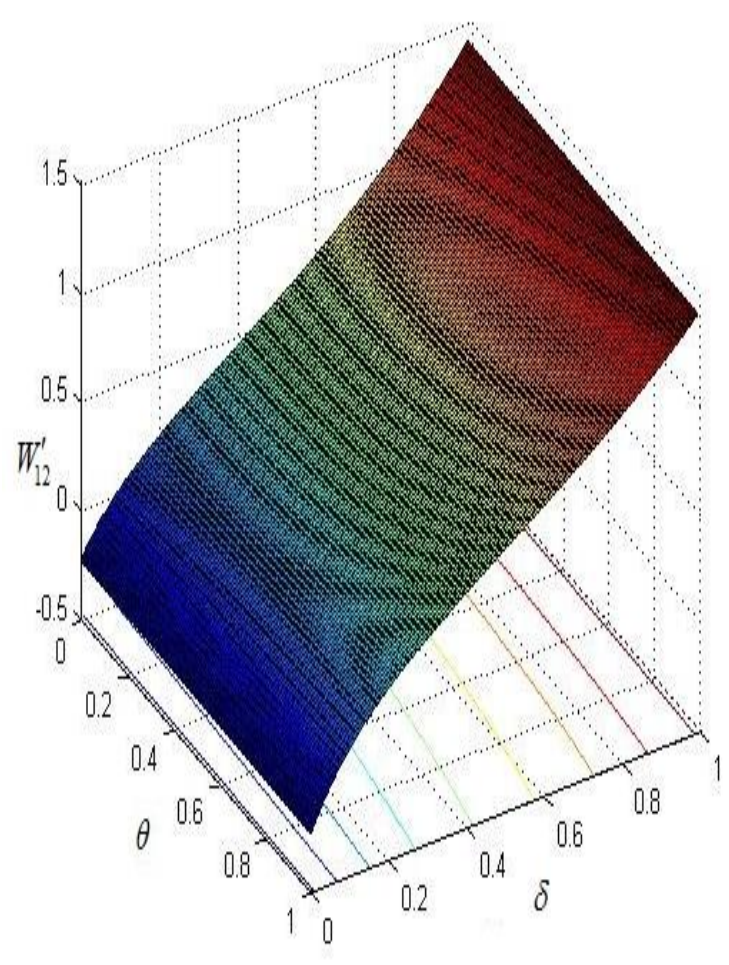

(a)

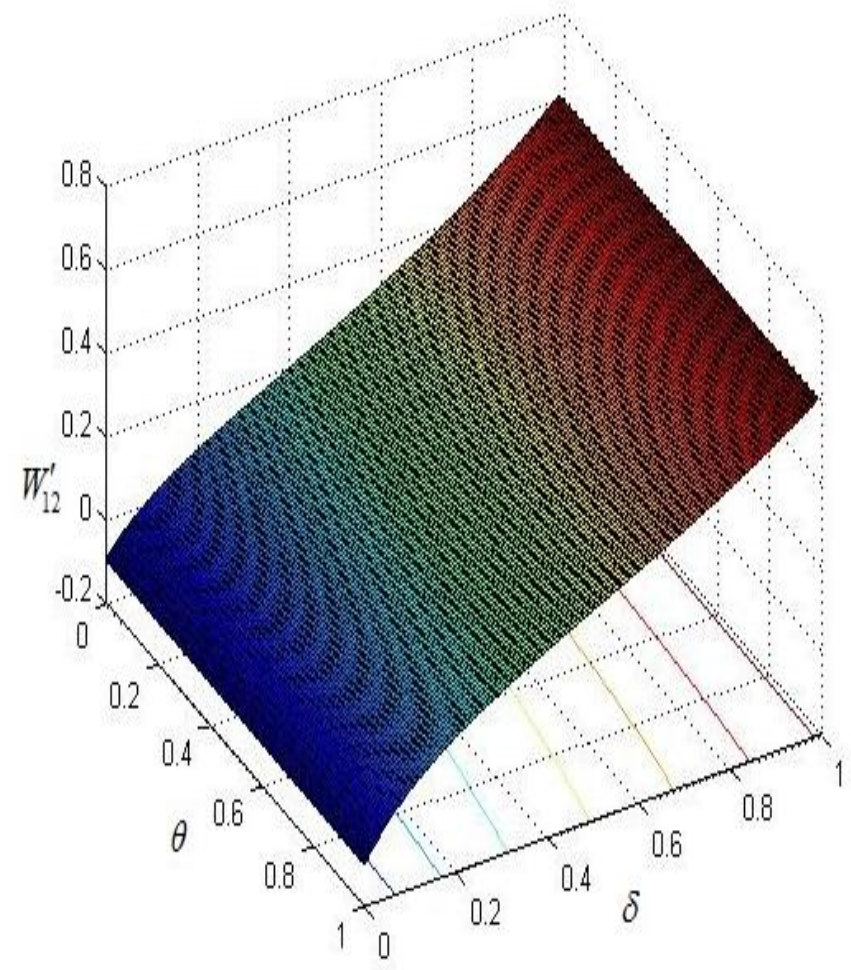

(b) 
Figure 7. Warranty curve of manufacturer 1 's product at market 1 with respect to $\delta$ and $\theta$ (a) when $\tau=0.3$ and (b) when $\tau=0.7$

Table 6. The effect of $\theta$ and $a_{1}$ on every variable in the presence of gray market

\begin{tabular}{clcccccccc}
\hline$\theta$ & $a_{1}$ & $p_{11}^{\prime}$ & $p_{21}^{\prime}$ & $p_{12}^{\prime}$ & $W_{12}^{\prime}$ & $p_{g}$ & $\pi_{M 1}^{\prime}$ & $\pi_{M 2}^{\prime}$ & $\pi_{g}$ \\
\hline 0.2 & 0.01 & 0.0088 & 0.0058 & 0.5488 & 0.8084 & 0.1063 & 0.0078 & 0.0035 & 0.05002 \\
0.2 & 0.1 & 0.0292 & 0.0529 & 0.5692 & 0.8278 & 0.1208 & 0.0634 & 0.03359 & 0.02731 \\
0.2 & 0.2 & 0.1438 & 0.1144 & 0.6838 & 0.9370 & 0.2028 & 0.10347 & 0.06542 & 0.01261 \\
0.2 & 0.3 & 0.1967 & 0.1696 & 0.7367 & 0.9873 & 0.2405 & 0.1290 & 0.09596 & 0.004718 \\
0.2 & 0.4 & 0.2410 & 0.2241 & 0.7810 & 1.0295 & 0.2721 & 0.1452 & 0.1256 & 0.001035 \\
0.2 & 0.5 & 0.2786 & 0.2779 & 0.8186 & 1.0653 & 0.2990 & 0.1552 & 0.1544 & $0.00000131 \mathrm{E}-05$ \\
0.4 & 0.01 & 0.0096 & 0.0069 & 0.5496 & 0.8091 & 0.1068 & 0.00922 & 0.004789 & 0.04973 \\
0.4 & 0.1 & 0.08649 & 0.06729 & 0.6264 & 0.8824 & 0.1618 & 0.07481 & 0.04529 & 0.02547 \\
0.4 & 0.3 & 0.2126 & 0.1925 & 0.7526 & 1.0025 & 0.2518 & 0.15064 & 0.1235 & 0.0031 \\
0.4 & 0.5 & 0.30006 & 0.31001 & 0.84006 & 1.0858 & 0.3143 & 0.18007 & 0.1922 & $0.2737777 \mathrm{E}-03$ \\
0.6 & 0.01 & 0.01066 & 0.0082 & 0.55066 & 0.8102 & 0.1076 & 0.01137 & 0.00672 & 0.04934 \\
0.6 & 0.1 & 0.0955 & 0.0786 & 0.6356 & 0.8910 & 0.1683 & 0.0913 & 0.06188 & 0.02314 \\
0.6 & 0.3 & 0.2328 & 0.2198 & 0.7728 & 1.0217 & 0.2663 & 0.1806 & 0.1611 & 0.001515 \\
0.6 & 0.5 & 0.3266 & 0.3480 & 0.8666 & 1.1111 & 0.3333 & 0.2134 & 0.2422 & 0.001479 \\
0.8 & 0.01 & 0.0121 & 0.0098 & 0.5521 & 0.8116 & 0.1086 & 0.0147 & 0.0097 & 0.04881 \\
0.8 & 0.1 & 0.1077 & 0.0931 & 0.6477 & 0.9026 & 0.1770 & 0.1161 & 0.0866 & 0.02018 \\
0.8 & 0.3 & 0.2589 & 0.2536 & 0.7989 & 1.0466 & 0.2850 & 0.2235 & 0.2143 & $0.3014337 \mathrm{E}-03$ \\
0.8 & 0.5 & 0.3600 & 0.3940 & 0.8999 & 1.1428 & 0.3571 & 0.2592 & 0.3104 & 0.0044 \\
\hline
\end{tabular}

Table 7. The effect of $\theta$ and $a_{2}$ on every variable in the presence of gray market (Note that since $a_{1}$ must always be lower than $a_{2}$ in this table for each value of $a_{2}, a_{1}$ is assumed the half $a_{2}$ value. For instance, in the first row that $a_{2}=0.1$, the value for $a_{1}$ would be 0.05 )

\begin{tabular}{cccccccccc}
\hline$\theta$ & $a_{2}$ & $p_{11}^{\prime}$ & $p_{21}^{\prime}$ & $p_{12}^{\prime}$ & $W_{12}^{\prime}$ & $p_{g}$ & $\pi_{M 1}^{\prime}$ & $\pi_{M 2}^{\prime}$ & $\pi_{g}$ \\
\hline 0.2 & 0.1 & 0.0306 & 0.02806 & 0.5706 & 1.5911 & 0.05328 & 0.0187 & 0.01575 & $0.3003645 \mathrm{E}-03$ \\
0.2 & 0.2 & 0.0658 & 0.0566 & 0.6058 & 1.4341 & 0.0956 & 0.0433 & 0.03202 & $0.1985881 \mathrm{E}-02$ \\
0.2 & 0.3 & 0.1011 & 0.0851 & 0.6411 & 1.2772 & 0.1378 & 0.0320 & 0.0483 & $0.3939492 \mathrm{E}-02$ \\
0.2 & 0.4 & 0.1363 & 0.1136 & 0.6763 & 1.1203 & 0.1802 & 0.0928 & 0.0646 & $0.5960126 \mathrm{E}-02$ \\
0.2 & 0.5 & 0.1715 & 0.1422 & 0.7115 & 0.9633 & 0.2225 & 0.1176 & 0.0808 & $0.8007569 \mathrm{E}-02$ \\
0.2 & 0.54 & 0.1856 & 0.1536 & 0.7256 & 0.9005 & 0.2394 & 0.1275 & 0.0873 & $0.8830717 \mathrm{E}-02$ \\
0.4 & 0.1 & 0.0333 & 0.0316 & 0.5733 & 1.5936 & 0.0552 & 0.0222 & 0.02005 & $0.1517445 \mathrm{E}-03$ \\
0.4 & 0.3 & 0.1094 & 0.0968 & 0.6494 & 1.2852 & 0.1438 & 0.0798 & 0.0626 & $0.2899662 \mathrm{E}-02$ \\
0.4 & 0.5 & 0.1855 & 0.1621 & 0.7255 & 0.9767 & 0.2325 & 0.1376 & 0.1051 & $0.6070400 \mathrm{E}-02$ \\
0.4 & 0.54 & 0.2008 & 0.1752 & 0.7408 & 0.9150 & 0.2503 & 0.1493 & 0.1136 & $0.6713944 \mathrm{E}-02$ \\
0.6 & 0.1 & 0.0368 & 0.0360 & 0.5768 & 1.5969 & 0.0576 & 0.0270 & 0.0260 & $0.3547496 \mathrm{E}-04$ \\
\hline
\end{tabular}




\begin{tabular}{llllllllll}
\hline 0.6 & 0.3 & 0.1202 & 0.1111 & 0.6602 & 1.2954 & 0.1515 & 0.0963 & 0.0822 & $0.1798712 \mathrm{E}-02$ \\
0.6 & 0.5 & 0.2036 & 0.1861 & 0.7436 & 0.9938 & 0.2454 & 0.1658 & 0.1385 & $0.3973984 \mathrm{E}-02$ \\
0.6 & 0.54 & 0.2202 & 0.2011 & 0.7602 & 0.9335 & 0.2642 & 0.1796 & 0.1497 & $0.4418195 \mathrm{E}-02$ \\
0.8 & 0.1 & 0.0412 & 0.0414 & 0.5812 & 1.6012 & 0.0608 & 0.0340 & 0.0344 & $0.5151279 \mathrm{E}-05$ \\
0.8 & 0.3 & 0.1342 & 0.1286 & 0.6742 & 1.3087 & 0.1615 & 0.1200 & 0.1104 & $0.7572379 \mathrm{E}-03$ \\
0.8 & 0.5 & 0.2271 & 0.2158 & 0.7671 & 1.0163 & 0.2622 & 0.2063 & 0.1863 & $0.1904943 \mathrm{E}-02$ \\
0.8 & 0.54 & 0.2456 & 0.2333 & 0.7856 & 0.9578 & 0.2823 & 0.2235 & 0.2015 & $0.2143275 \mathrm{E}-02$ \\
\hline
\end{tabular}

Table 8. The effect of $\theta$ and $\delta$ on every variable in the presence of gray market

\begin{tabular}{|c|c|c|c|c|c|c|c|c|c|}
\hline$\theta$ & $\delta$ & $p_{11}$ & $p_{21}$ & $p_{12}^{\prime}$ & $W_{12}^{\prime}$ & $p_{g}$ & $\pi_{M 1}^{\prime}$ & $\pi_{M 2}^{\prime}$ & $\pi_{g}$ \\
\hline 0.01 & 0.1 & 0.0851 & 0.2004 & 0.6251 & 0.3203 & 0.0790 & 0.0181 & 0.1004 & $0.1512069 \mathrm{E}-01$ \\
\hline 0.01 & 0.2 & 0.1373 & 0.2007 & 0.6773 & 0.4849 & 0.1318 & 0.0471 & 0.1007 & $0.8111818 \mathrm{E}-02$ \\
\hline 0.01 & 0.3 & 0.1698 & 0.2008 & 0.7098 & 0.6213 & 0.1734 & 0.0721 & 0.1008 & $0.2557026 \mathrm{E}-02$ \\
\hline 0.01 & 0.5 & 0.2111 & 0.2011 & 0.7511 & 0.8790 & 0.2374 & 0.1114 & 0.1011 & $0.3178427 \mathrm{E}-03$ \\
\hline 0.01 & 0.7 & 0.2404 & 0.2012 & 0.7804 & 1.1644 & 0.2811 & 0.1445 & 0.1012 & $0.4072355 \mathrm{E}-02$ \\
\hline 0.01 & 0.9 & 0.2669 & 0.2013 & 0.8069 & 1.5172 & 0.3017 & 0.1781 & 0.1013 & $0.4885270 \mathrm{E}-02$ \\
\hline 0.1 & 0.1 & 0.0880 & 0.2044 & 0.6280 & 0.3250 & 0.0805 & 0.0194 & 0.1044 & $0.1679480 \mathrm{E}-01$ \\
\hline 0.1 & 0.3 & 0.1751 & 0.2088 & 0.7151 & 0.6285 & 0.1765 & 0.0766 & 0.1089 & $0.3281601 \mathrm{E}-02$ \\
\hline 0.1 & 0.5 & 0.2173 & 0.2108 & 0.7573 & 0.8859 & 0.2415 & 0.1181 & 0.1112 & $0.1431244 \mathrm{E}-03$ \\
\hline 0.1 & 0.7 & 0.2471 & 0.2124 & 0.7871 & 1.1695 & 0.2862 & 0.1526 & 0.1127 & $0.3488083 \mathrm{E}-02$ \\
\hline 0.1 & 0.9 & 0.2738 & 0.2136 & 0.8138 & 1.5193 & 0.3080 & 0.1874 & 0.1142 & $0.4481069 \mathrm{E}-02$ \\
\hline 0.2 & 0.1 & 0.0915 & 0.2091 & 0.6314 & 0.3304 & 0.0824 & 0.0209 & 0.1094 & $0.1884724 \mathrm{E}-01$ \\
\hline 0.2 & 0.3 & 0.1815 & 0.2182 & 0.7215 & 0.6372 & 0.1802 & 0.0823 & 0.1190 & $0.4275527 \mathrm{E}-02$ \\
\hline 0.2 & 0.5 & 0.2249 & 0.2224 & 0.7649 & 0.8944 & 0.2466 & 0.1265 & 0.1238 & $0.2271115 \mathrm{E}-04$ \\
\hline 0.2 & 0.7 & 0.2553 & 0.2255 & 0.7954 & 1.1759 & 0.2926 & 0.1630 & 0.1272 & $0.2825467 \mathrm{E}-02$ \\
\hline 0.2 & 0.9 & 0.2824 & 0.2282 & 0.8224 & 1.5220 & 0.3159 & 0.1994 & 0.1302 & $0.3998711 \mathrm{E}-02$ \\
\hline 0.3 & 0.1 & 0.0951 & 0.2142 & 0.6351 & 0.3361 & 0.0842 & 0.0226 & 0.1148 & $0.2112864 \mathrm{E}-01$ \\
\hline 0.3 & 0.3 & 0.1884 & 0.2282 & 0.7284 & 0.6468 & 0.1844 & 0.0888 & 0.1302 & $0.5511004 \mathrm{E}-02$ \\
\hline 0.3 & 0.5 & 0.2334 & 0.2350 & 0.7734 & 0.9038 & 0.2522 & 0.1362 & 0.1381 & $0.1042882 \mathrm{E}-04$ \\
\hline 0.3 & 0.7 & 0.2646 & 0.2397 & 0.8046 & 1.1831 & 0.2997 & 0.1751 & 0.1436 & $0.2164598 \mathrm{E}-02$ \\
\hline 0.3 & 0.9 & 0.2922 & 0.2438 & 0.8322 & 1.5249 & 0.3247 & 0.2135 & 0.1486 & $0.3485512 \mathrm{E}-02$ \\
\hline 0.5 & 0.1 & 0.1029 & 0.2257 & 0.6429 & 0.3484 & 0.0884 & 0.0264 & 0.1274 & $0.2651220 \mathrm{E}-01$ \\
\hline 0.5 & 0.3 & 0.2044 & 0.2511 & 0.7444 & 0.6688 & 0.1938 & 0.1044 & 0.1576 & $0.8941376 \mathrm{E}-02$ \\
\hline 0.5 & 0.5 & 0.2534 & 0.2633 & 0.7933 & 0.9259 & 0.2656 & 0.1604 & 0.1734 & $0.4855187 \mathrm{E}-03$ \\
\hline 0.5 & 0.7 & 0.2868 & 0.2717 & 0.8268 & 1.2002 & 0.3168 & 0.2058 & 0.1846 & $0.9429046 \mathrm{E}-03$ \\
\hline 0.5 & 0.9 & 0.3158 & 0.2790 & 0.8558 & 1.5321 & 0.3462 & 0.2494 & 0.1945 & $0.2392692 \mathrm{E}-02$ \\
\hline 0.7 & 0.1 & 0.1116 & 0.2391 & 0.6516 & 0.3623 & 0.0930 & 0.0312 & 0.1429 & $0.3327742 \mathrm{E}-01$ \\
\hline 0.7 & 0.3 & 0.2238 & 0.2783 & 0.7638 & 0.6954 & 0.2052 & 0.1252 & 0.1936 & $0.1421595 \mathrm{E}-01$ \\
\hline 0.7 & 0.5 & 0.2783 & 0.2974 & 0.8183 & 0.9536 & 0.2822 & 0.1936 & 0.2211 & $0.2075613 \mathrm{E}-02$ \\
\hline 0.7 & 0.7 & 0.3151 & 0.3103 & 0.8551 & 1.2219 & 0.3386 & 0.2483 & 0.2407 & $0.1120363 \mathrm{E}-03$ \\
\hline
\end{tabular}




\begin{tabular}{llllllllll}
\hline 0.7 & 0.9 & 0.3462 & 0.3212 & 0.8862 & 1.5412 & 0.3738 & 0.2997 & 0.2579 & $0.1288070 \mathrm{E}-02$ \\
0.9 & 0.1 & 0.1216 & 0.2547 & 0.6616 & 0.3781 & 0.0982 & 0.0370 & 0.1622 & $0.4189385 \mathrm{E}-01$ \\
0.9 & 0.3 & 0.2478 & 0.3115 & 0.7878 & 0.7283 & 0.2192 & 0.1535 & 0.2426 & $0.2240477 \mathrm{E}-01$ \\
0.9 & 0.5 & 0.3101 & 0.3395 & 0.8501 & 0.9889 & 0.3034 & 0.2404 & 0.2882 & $0.5700472 \mathrm{E}-02$ \\
0.9 & 0.7 & 0.3516 & 0.3583 & 0.8916 & 1.2500 & 0.3666 & 0.3092 & 0.3208 & $0.2384867 \mathrm{E}-03$ \\
0.9 & 0.9 & 0.3859 & 0.3736 & 0.9259 & 1.5533 & 0.4099 & 0.3724 & 0.3491 & $0.3563257 \mathrm{E}-03$ \\
\hline
\end{tabular}

\subsection{The scenario without the presence of the gray market}

As the level of substitutability rises in market 1 , both manufacturers increase their prices equally. However, this rise in their prices always results in a lower price than the price that manufacturer 1 sets at market 2 , which is reasonable since the willingness to pay for market 2 is higher than willingness to pay in market 1 . Moreover, as the willingness to pay in market 1 increases, both manufacturers tend to set higher values for their prices.

Note that the price set by manufacturer 1 at market 2 does not depend on the level of substitutability and only depends on the willingness to pay at market 2 , i.e. if the customers are more willing to pay, then manufacturer 1 chooses a higher price in order to receive more benefit.

In the first scenario, even though offering warranty has a positive effect on the demand of manufacturer 1 's product at market 2 , it also creates additional costs in the profit function. Therefore, despite the fact that manufacturer 1 offers the product in two markets, the profits of manufacturer 2 from his/her sales at market 1 alone, is equal to the total sales of manufacturer 1 at both markets. However, it can be observed in the following section that this situation does not hold in the presence of the gray market and the result is an increase in the profit of manufacturer 1.

\subsection{The scenario with the presence of the gray market}

At market 1, as the level of compatibility increases between two products, manufacturer 1 sets a relatively higher price. When the two products are not substitutable, manufacturer 1 decides on his price individually. If the popularity of the gray market increases among market 2 , manufacturer 1 decides on a higher price for market 1 , but as it passes a mid-point, manufacturer 1 decreases his price again. If the market has a higher willingness to pay, or if the two products are more substitutable, or if manufacturer 1 sets a higher price, manufacturer 2 raises his price. On the other hand, if the two products are not substitutable, manufacturer 2 sets a price without considering the price of manufacturer 1 and only takes into account the willingness to pay of customers in market 1 .

At market 2, an increase in the probability of gray market, causes an increase in the price that manufacturer 1 sets for market 2, which after a while reverses. It can be concluded that the price that manufacturer 1 sets at market 2 is always higher of the price in market 1 , since it is assumed that failure of products occurs and it always results in a cost for the company. Moreover, as the decreasing effect of gray market reaches a low enough value, the conditions are similar to that 

importer; thus, manufacturer 1 sets a lower warranty time. Additionally, as the popularity of the gray market increases, parallel importer sets a higher price, but this effect reverses in time as well. Furthermore, gray market sets a higher price when products are more substitutable.

In the second scenario, when the gray market is in play, manufacturer 1 tends to decrease the price for market 1 , but decrease the price of market 2 in the case that manufacturer 1 offers warranty to compete with the gray market. On the contrary, in a case without offering warranty, it is better for that manufacturer to limit the activities of the parallel importation, and in order to do that, manufacturer 1 sets a higher price at market 1 and a lower price at market 2 .

By offering warranty, manufacturer 1 increases his own profit when he competes with the parallel importer. Nevertheless, setting a lower price at market 1 causes manufacturer 2 to also decrease his price to maintain in the competition and keep his demand as before, and since manufacturer 2 has a similar situation and the only difference is that he decreased the price, then his profit drops in comparison to the scenario where gray market does not exist.

Additionally, when competing with the parallel importer at market 2, manufacturer 1 increases his warranty length, which acts as an incentive for the segment of market 2 that has a higher willingness to pay and tend to purchase from the authorized channel. It can be concluded that by creating a larger gap between the prices among the two markets, manufacturer 1 has a higher demand at market 1 due to the purchase of the gray market, and by increasing his price at market 2 while increasing the duration period of his warranty, he does not decrease his chances of competiveness against gray market.

At the low level of compatibility and when manufacturers set a lower price at the first market due to customers' willingness to pay then the manufacturers have lower profits. As customers' willingness to pay and the level of compatibility between two manufacturers rises, thus their profits rise. Similar situation occurs as the willingness to pay for customers at market 2 rises. Both manufacturers experience an increment in their profits. However, this situation does not hold for the profit of the gray market, whereas the parallel importer's profit decreases as the level of compatibility or customers' willingness to pay at market 1 increases. Gray market benefits when customers at market 1 have the lowest willingness to pay. The profit of gray market increases as the willingness to pay for customers at market 2 increases, but a lower willingness to pay at market 1 has more effect on the profit of the parallel importer than a higher willingness to pay at market 2. Moreover, as the level of popularity of the gray market rises the profit of that channel increases. The level of popularity of the gray market has less effect on the profit of manufacturer 2. However, as customers become more prone to gray market, manufacturer 1's benefit from its sales increases. Note that in this problem the profit for any of the two manufacturers reaches its maximum when it is close to 1 , therefore, the values of the profits may seem low, but in real life scenarios they may be multiplied by millions.

\section{Conclusion and future research directions}


As mentioned before, warranty is introduced as an important factor to face gray market's challenges. Therefore, it seems that this factor must be considered when modeling a problem with parallel importation. However, to the best of our knowledge, any previous work has neglected to include warranty as a competing factor with gray market. Thus, to attain a better understanding of the effects of parallel importation on price and warranty of different firms involved, warranty has been studied and analyzed in this paper. The problem of an autonomous party that acts as the gray market is faced by any company that offers products in different markets with price differentiation. Examples in real life include companies that provide electronic devices, such as laptops, cell phones, digital cameras, and other similar products.

Basically, in this paper, two markets are being analyzed, one with low willingness to pay, and another with higher willingness to pay. Two manufacturers compete in the first market selling their substitutable products. Manufacturer 1 considers offering warranty when parallel importation from market 1 with lower willingness to pay, to market 2 with higher willingness to pay is carried on by a third party that purchases manufacturer 1's product at market 1 and sells it at market 2. Two scenarios with and without the presence of parallel importation are studied and analyzed. Without the presence of the gray market, the manufacturers compete by setting equal prices in market 1 , whereas in market 2, manufacturer 2 sets its appropriate price when he has monopoly over this market. However, in the second case when gray market is present, in the market 1 , it can be concluded that manufacturer 2 sets higher prices that manufacturer 1 . Manufacturer 1 compensates this lower price by setting a higher price at market 2 when he is in competition with the parallel importer. Furthermore, the competition between manufacturer 1 and parallel importer in market 2 is categorized as a Stackelberg game where manufacturer 1 is the leader and parallel importer acts as the follower, since the price of the parallel importer depends on the price manufacturer 1 sets at market 1 .

A limitation facing this work is that the problem defined in this paper is not dynamic. Studying this problem under more than one period may result differently than what it was concluded here. Moreover, in order to create a more realistic scenario one may include other variables. For instance, for future research other aspects such as advertisement, return policies, quality, among others must be considered in the model as additional variables in the demand function.

\section{References}

Ahmadi, R., Iravani, F., Mamani, H. (2015). Coping with gray markets: The impacts of market conditions and product characteristics. Production and Operations Management, 24(5), 762-777.

Autrey, R.L., Bova, F., Soberman, D.A. (2015). When gray is good: Gray markets and market-creating investments. Production and Operations Management, 24(4), 547-559.

Blischke, W. (1993). Warranty cost analysis: Taylor \& Francis.

Chaudhry, P. E. (2014). Confronting the gray market problem. Business Economics, 49(4), 263-270.

Chen, X., Li, L., Zhou, M. (2012). Manufacturer's pricing strategy for supply chain with warranty perioddependent demand. Omega, 40(6), 807-816. 
Christensen, G. J. (2010). Are you using "gray-market" or counterfeit dental products? The Journal of the American Dental Association, 141(6), 712-715.

Chukova, S., Hayakawa, Y., Dohi, T., Karim, R., Suzuki, K. (2005). Analysis of warranty claim data: a literature review. International Journal of Quality \& Reliability Management, 22(7), 667-686.

Chun, Y. H., Tang, K. (1995). Determining the optimal warranty price based on the producer's and customers' risk preferences. European Journal of Operational Research, 85(1), 97-110.

Cross, J., Stephans, J., Benjamin, R. E. (1990). Gray markets: A legal review and public policy perspective. Journal of Public Policy and Marketing, 9, 183-194.

Dai, Y., Zhou, S. X., Xu, Y. (2012). Competitive and collaborative quality and warranty management in supply chains. Production and Operations Management, 21(1), 129-144.

DeCroix, G. A. (1999). Optimal warranties, reliabilities and prices for durable goods in an oligopoly. European Journal of Operational Research, 112(3), 554-569.

Duhan, D. F., Sheffet, M. J. (1988). Gray markets and the legal status of parallel importation. The Journal of Marketing, 52, 75-83.

Howell, R. D., Britney, R. R., Kuzdrall, P. J., Wilcox, J. B. (1986). Unauthorized channels of distribution: Gray markets. Industrial Marketing Management, 15(4), 257-263.

Huang, Y., Huang, G. Q., Gang, K. I. (2013). Dynamic game-theoretic model for coordinating pricing and inventory decisions in a supply chain with retailer competition. Paper presented at the 2013 the International Conference on Education Technology and Information System (ICETIS 2013).

Jalali, M.H., Moghaddam, F.M. (In Press). Factors influencing customers' attitude toward gray market. International Journal of Business and Marketing.

Jelovac, I., Bordoy, C. (2005). Pricing and welfare implications of parallel imports in the pharmaceutical industry. International Journal of Health Care Finance and Economics, 5(1), 5-21.

Lan, Y., Zhao, R., Tang, W. (2014). A fuzzy supply chain contract problem with pricing and warranty. Journal of Intelligent and Fuzzy Systems: Applications in Engineering and Technology, 26(3), 15271538 .

Li, K., Geng, Q., Shao, B. (2011). Warranty Designs and Brand Reputation Analysis in a Duopoly. California Journal of Operations Management, 9(1), 34-42.

Li, X., Nukala, S., Mohebbi, S. (2013). Game theory methodology for optimizing retailers' pricing and shelf-space allocation decisions on competing substitutable products. The International Journal of Advanced Manufacturing Technology, 68(1-4), 375-389.

Ma, L., Zhang, R., Guo, S., Liu, B. (2012). Pricing decisions and strategies selection of dominant manufacturer in dual-channel supply chain. Economic Modelling, 29(6), 2558-2565.

Menezes, M. A., Currim, I. S. (1992). An approach for determination of warranty length. International Journal of Research in Marketing, 9(2), 177-195.

Modak, N. M., Panda, S., Sana, S. S., Nisar, T. (2015). Managing a two-echelon supply chain with price, warranty and quality dependent demand. Cogent Business and Management, 2(1), 1011014.

Murthy, D., Djamaludin, I. (2002). New product warranty: A literature review. International Journal of Production Economics, 79(3), 231-260.

Shavandi, H., Valizadeh Khaki, S., Khedmati, M. (2014). Parallel importation and price competition in a duopoly supply chain. International Journal of Production Research, 53(10), 3104-3119.

Sinha, S., Sarmah, S. (2011). Price and warranty competition in a duopoly supply chain. In book: Supply Chain Coordination under Uncertainty (pp. 281-314). Springer. 
Su, X., Mukhopadhyay, S.K. (2012). Controlling power retailer's gray activities through contract design. Production and Operations Management, 21(1), 145-160.

Thompson, S. (2009). Grey power: An empirical investigation of the impact of parallel imports on market prices. Journal of Industry, Competition and Trade, 3(9), 219-232.

Tsao, Y.C., Teng, W.G., Chen, R.S., Chou, W.Y. (2014). Pricing and inventory policies for hi-tech products under replacement warranty. International Journal of Systems Science, 45(6), 1255-1267.

Wei, J., Zhao, J. (2016). Pricing decisions for substitutable products with horizontal and vertical competition in fuzzy environments. Annals of Operations Research, 242 (2), 505-528.

Wei, J., Zhao, J., Li, Y. (2015). Price and warranty period decisions for complementary products with horizontal firms' cooperation/noncooperation strategies. Journal of Cleaner Production, 105, 86-102.

Wu, C.H. (2012). Price and service competition between new and remanufactured products in a twoechelon supply chain. International Journal of Production Economics, 140(1), 496-507.

Wu, S. (2012). Warranty data analysis: a review. Quality and Reliability Engineering International, 28(8), 795-805.

Wu, S. (2013). A review on coarse warranty data and analysis. Reliability Engineering \& System Safety, $114,1-11$

$\mathrm{Wu}, \mathrm{S}$. (2014). Warranty return policies for products with unknown claim causes and their optimisation. International Journal of Production Economics, 156, 52-61.

$\mathrm{Xu}$, B., Zhou, F. (2012). Research on supply chain versus supply chain competition with product quality and price dependent demand. Paper presented at the Automation and Logistics (ICAL), 2012 IEEE International Conference.

Zhao, J., Tang, W., Wei, J. (2012). Pricing decision for substitutable products with retail competition in a fuzzy environment. International Journal of Production Economics, 135(1), 144-153.

Zhao, J., Wei, J., Li, Y. (2014). Pricing decisions for substitutable products in a two-echelon supply chain with firms' different channel powers. International Journal of Production Economics, 153, 243-252.

\section{Appendix A. Proof of Proposition 1}

First derivatives of each manufacturer's profit function with regards to each decision variable, provides the optimal values for decision variables. First, the price for manufacturer 2 is determined as

$$
\frac{\partial \pi_{M 2}}{\partial p_{21}}=1-\frac{p_{21}}{a_{1}}+\theta \frac{p_{11}}{a_{1}}-\frac{p_{21}}{a_{1}}=0 \rightarrow p_{21}=\frac{a_{1}}{2}+\theta \frac{p_{11}}{2}
$$

The second derivative of the decision variable of manufacturer 2 is $-\frac{2}{a_{1}}<0$, which means the profit function is concave, therefore, the value for the decision variable of manufacturer 2 optimizes the profit function.

The profit function of manufacturer 1 is given by 
$\pi_{M 1}\left(p_{11}, p_{12}, W_{12}\right)=\left[1-\frac{p_{11}}{a_{1}}+\frac{\theta p_{21}}{a_{1}}\right] p_{11}+\left[1-\frac{p_{12}}{a_{2}}+\lambda W_{12}\right]\left(p_{12}-r_{1} c_{1}\right)$

Taking the first derivative $\pi_{M 1}$ with respect to $p_{11}$

$\frac{\partial \pi_{M 1}\left(p_{11}, p_{12}, W_{12}\right)}{\partial p_{11}}=-\frac{p_{11}}{a_{1}}+\left[1-\frac{p_{11}}{a_{1}}+\frac{\theta p_{21}}{a_{1}}\right]=0$

Substituting A1 into A2 and solving for $p_{11}$ then

$$
p_{11}=\frac{a_{1}}{(2-\theta)}
$$

Now, substituting A3 into A1 thus

$$
p_{21}=\frac{a_{1}}{(2-\theta)}
$$

Taking the first derivative of $\pi_{M 1}$ with respect to $W_{12}$

$$
\frac{\partial \pi_{M 1}\left(p_{11}, p_{12}, W_{12}\right)}{\partial W_{12}}=\lambda\left(p_{12}-r_{1} c_{1}\right)=0
$$

This implies that

$$
p_{12}=r_{1} c_{1}
$$

Taking the first derivative of $\pi_{M 1}$ with respect to $p_{12}$

$$
\frac{\partial \pi_{M 1}\left(p_{11}, p_{12}, W_{12}\right)}{\partial p_{12}}=-\frac{\left(p_{12}-r_{1} c_{1}\right)}{a_{2}}+\left[1-\frac{p_{12}}{a_{2}}+\lambda W_{12}\right]=0
$$

Hence,

$$
p_{12}=\frac{r_{1} c_{1}}{2}+\frac{\left(1+\lambda W_{12}\right) a_{2}}{2}
$$

Substituting A6 into A8 thus

$$
W_{12}=\frac{1}{\lambda}\left[\frac{r_{1} c_{1}}{a_{2}}-1\right]
$$

In order to prove optimality, the Hessian matrix is determined. 


$$
H_{A}=\left(\begin{array}{ccc}
\frac{\partial^{2} \pi_{M 1}}{\partial p_{11}^{2}} & \frac{\partial^{2} \pi_{M 1}}{\partial p_{12} \partial p_{11}} & \frac{\partial^{2} \pi_{M 1}}{\partial W_{12} \partial p_{11}} \\
\frac{\partial^{2} \pi_{M 1}}{\partial p_{12} \partial p_{11}} & \frac{\partial^{2} \pi_{M 1}}{\partial p_{12}{ }^{2}} & \frac{\partial^{2} \pi_{M 1}}{\partial W_{12} \partial p_{12}} \\
\frac{\partial^{2} \pi_{M 1}}{\partial W_{12} \partial p_{11}} & \frac{\partial^{2} \pi_{M 1}}{\partial W_{12} \partial p_{12}} & \frac{\partial^{2} \pi_{M 1}}{\partial W_{12}^{2}}
\end{array}\right)=\left(\begin{array}{ccc}
\frac{-2}{a_{1}} & 0 & 0 \\
0 & \frac{-2}{a_{2}} & \lambda \\
0 & \lambda & 0
\end{array}\right)
$$

Notice that the principal diagonals are negative implying that the hessian matrix is negative definite. Therefore, the decision variables $\left(p_{11}, p_{12}, W_{12}\right)$ optimize the profit function of manufacturer 1 and these results corresponds to a global optimal solution. Based on these calculations optimum solutions for the variables are shown in Proposition 1, Equations 7-10.

\section{Appendix B. Proof of Proposition 2}

First derivatives of each manufacturer's profit function with regards to each decision variable, gives the optimal values for the decision variables. First, the price of manufacturer 2, which is calculated by setting the first derivative with respect to price equal to zero, thus,

$\frac{\partial \pi_{M 2}^{\prime}}{\partial p_{21}^{\prime}}=\left[1-\frac{p_{21}^{\prime}}{a_{1}}+\theta \frac{p_{11}^{\prime}}{a_{1}}\right]-\frac{p_{21}^{\prime}}{a_{1}}=0 \rightarrow p_{21}^{\prime}=\frac{a_{1}}{2}+\theta \frac{p_{11}^{\prime}}{2}$

(B1)

Furthermore, for finding the price of the parallel importation, again the first derivative of the gray market's profit function with respect to the price is obtained as follows,

$$
\frac{\partial \pi_{g}}{\partial p_{g}}=\frac{\delta p_{12}^{\prime}-\delta \tau W_{12}^{\prime}-p_{g}}{\delta(1-\delta) a_{2}}-\frac{p_{g}-p_{11}^{\prime}-c_{t}}{\delta(1-\delta) a_{2}}=0 \rightarrow p_{g}=\frac{\delta p_{12}^{\prime}}{2}-\frac{\delta \tau W_{12}^{\prime}}{2}+\frac{p_{11}^{\prime}}{2}+\frac{c_{t}}{2}
$$

Notice that the second derivative of these decision variables $\left(p_{21}^{\prime}, p_{g}\right)$ are negative, therefore the values for these prices corresponds to a global optimal solution.

The profit function of manufacturer 1 is given by

$$
\pi_{M 1}^{\prime}\left(p_{11}^{\prime}, p_{12}^{\prime}, W_{12}^{\prime}\right)=\left[\left(1-\frac{p_{11}^{\prime}}{a_{1}}+\frac{\theta p_{21}^{\prime}}{a_{1}}\right)+\frac{\delta p_{12}^{\prime}-\delta \tau W_{12}^{\prime}-p_{g}}{\delta(1-\delta) a_{2}}\right] p_{11}+\left[1-\frac{p_{12}^{\prime}-\tau W_{12}^{\prime}-p_{g}}{a_{2}(1-\delta)}\right]\left(p_{12}^{\prime}-r_{1} c_{1}\right)
$$

Taking the first derivative of $\pi_{M 1}^{\prime}$ with respect to $p_{11}^{\prime}$ 


$$
\frac{\partial \pi_{M 1}^{\prime}}{\partial p_{11}^{\prime}}=\frac{\left[\left(\theta^{2}-4\right) \delta(1-\delta) a_{2}-a_{1}\right] p_{11}^{\prime}+\delta a_{1} p_{12}^{\prime}-\delta a_{1} \tau W_{12}^{\prime}+a_{1} a_{2} \delta(1-\delta)(\theta+2)-a_{1} c_{t}}{2 \delta(1-\delta) a_{1} a_{2}}=0
$$

This implies

$$
\left[\left(\theta^{2}-4\right) \delta(1-\delta) a_{2}-a_{1}\right] p_{11}^{\prime}+\delta a_{1} p_{12}^{\prime}-a_{1} \delta \tau W_{12}^{\prime}=a_{1} c_{t}-a_{1} a_{2} \delta(1-\delta)(\theta+2)
$$

Taking the first derivative of $\pi_{M 1}^{\prime}$ with respect to $p_{12}^{\prime}$

$$
\frac{\partial \pi_{M 1}^{\prime}}{\partial p_{12}^{\prime}}=\frac{3 p_{11}^{\prime}-(4-\delta) p_{12}^{\prime}+\tau(2-\delta) W_{12}^{\prime}+2 r_{1} c_{1}+2 a_{2}(1-\delta)+c_{t}}{2 a_{2}(1-\delta)}=0
$$

This implies

$$
3 p_{11}^{\prime}-(4-\delta) p_{12}^{\prime}+\tau(2-\delta) W_{12}^{\prime}=-\left[c_{t}+2 a_{2}(1-\delta)+2 r_{1} c_{1}\right]
$$

Taking the first derivative of $\pi_{M 1}^{\prime}$ with respect to $W_{12}^{\prime}$

$$
\frac{\partial \pi_{M 1}^{\prime}}{\partial W_{12}^{\prime}}=\frac{-\tau p_{11}^{\prime}+\tau\left(p_{12}^{\prime}-r_{1} c_{1}\right)}{a_{2}(1-\delta)}=0
$$

Thus,

$$
p_{12}^{\prime}=p_{11}^{\prime}+r_{1} c_{1}
$$

Solving the three equations B3, B4 and B5 simultaneously, hence the optimal solutions are:

$$
\begin{aligned}
& p_{11}^{\prime}=\frac{a_{1} a_{2} \delta(\delta-1)\{(2-\delta)(\theta+2)+2\}-2 a_{1} c_{t}(\delta-1)}{\left(\theta^{2}-4\right) \delta(1-\delta)(2-\delta) a_{2}+2 a_{1}(\delta-1)} \\
& p_{12}^{\prime}=r_{1} c_{1}+\frac{a_{1} a_{2} \delta(\delta-1)\{(2-\delta)(\theta+2)+2\}-2 a_{1} c_{t}(\delta-1)}{\left(\theta^{2}-4\right) \delta(1-\delta)(2-\delta) a_{2}+2 a_{1}(\delta-1)}
\end{aligned}
$$

and

$$
W_{12}^{\prime}=\frac{(2-\delta) r_{1} c_{1}-2 a_{2}(1-\delta)-c_{t}}{\tau(2-\delta)}+\frac{(1-\delta)}{(2-\delta) \tau} \frac{a_{1} a_{2} \delta(\delta-1)\{(2-\delta)(\theta+2)+2\}-2 a_{1} c_{t}(\delta-1)}{\left(\theta^{2}-4\right) \delta(1-\delta)(2-\delta) a_{2}+2 a_{1}(\delta-1)}
$$

Substituting $p_{11}^{\prime}$ into B1 thus 


$$
p_{21}^{\prime}=\frac{a_{1}}{2}+\frac{\theta}{2} \frac{a_{1} a_{2} \delta(\delta-1)\{(2-\delta)(\theta+2)+2\}-2 a_{1} c_{t}(\delta-1)}{\left(\theta^{2}-4\right) \delta(1-\delta)(2-\delta) a_{2}+2 a_{1}(\delta-1)}
$$

Substituting $p_{11}^{\prime}, p_{12}^{\prime}, W_{12}^{\prime}$ into $\mathrm{B} 2$ hence

$$
p_{g}^{\prime}=\frac{a_{2} \delta(1-\delta)+c_{t}}{(2-\delta)}+\frac{1}{(2-\delta)} \frac{a_{1} a_{2} \delta(\delta-1)\{(2-\delta)(\theta+2)+2\}-2 a_{1} c_{t}(\delta-1)}{\left(\theta^{2}-4\right) \delta(1-\delta)(2-\delta) a_{2}+2 a_{1}(\delta-1)}
$$

In order to prove optimality, the Hessian matrix is determined.

$$
H_{B}=\left(\begin{array}{ccc}
\frac{\partial^{2} \pi_{M 1}^{\prime}}{\partial p_{11}^{\prime 2}} & \frac{\partial^{2} \pi_{M 1}^{\prime}}{\partial p_{11}^{\prime} \partial p_{12}^{\prime}} & \frac{\partial^{2} \pi_{M 1}^{\prime}}{\partial W_{12}^{\prime} \partial p_{11}^{\prime}} \\
\frac{\partial^{2} \pi_{M 1}^{\prime}}{\partial p_{12}^{\prime} \partial p_{11}^{\prime}} & \frac{\partial^{2} \pi_{M 1}^{\prime}}{\partial p_{12}^{\prime 2}} & \frac{\partial^{2} \pi_{M 1}^{\prime}}{\partial W_{12}^{\prime} \partial p_{12}^{\prime}} \\
\frac{\partial^{2} \pi_{M 1}^{\prime}}{\partial W_{12}^{\prime} \partial p_{11}^{\prime}} & \frac{\partial^{2} \pi_{M 1}^{\prime}}{\partial W_{12}^{\prime} \partial p_{12}^{\prime}} & \frac{\partial^{2} \pi_{M 1}^{\prime}}{\partial W_{12}^{\prime 2}}
\end{array}\right)=\left(\begin{array}{ccc}
\frac{\left[\left(\theta^{2}-4\right) \delta(1-\delta) a_{2}-a_{1}\right]}{2 \delta(1-\delta) a_{1} a_{2}} & \frac{1}{2(1-\delta) a_{2}} & -\frac{\tau}{2(1-\delta) a_{2}} \\
\frac{1}{2(1-\delta) a_{2}} & -\frac{(4-\delta)}{2 a_{2}(1-\delta)} & \frac{\tau(2-\delta)}{2 a_{2}(1-\delta)} \\
-\frac{\tau}{2(1-\delta) a_{2}} & \frac{\tau(2-\delta)}{2 a_{2}(1-\delta)} & 0
\end{array}\right)
$$

It is assumed that $\theta<1$ therefore that the principal diagonals are negative implying that the hessian matrix is negative definite. Therefore, the decision variables $\left(p_{11}^{\prime}, p_{12}^{\prime}, W_{12}^{\prime}\right)$ optimize the profit function of manufacturer 1 and these results corresponds to a global optimal solution. 